\title{
Volcanic synchronization of Dome Fuji and Dome C Antarctic deep ice cores over the past $216 \mathrm{kyr}$
}

\author{
S. Fujita ${ }^{1,2, *}$, F. Parrenin ${ }^{3,4, *}$, M. Severi ${ }^{5}$, H. Motoyama ${ }^{1,2}$, and E. W. Wolff ${ }^{6}$ \\ ${ }^{1}$ National Institute of Polar Research, Research Organization of Information and Systems, Tokyo, Japan \\ ${ }^{2}$ Department of Polar Science, The Graduate University for Advanced Studies (SOKENDAI), Tokyo, Japan \\ ${ }^{3}$ CNRS, LGGE, 38041 Grenoble, France \\ ${ }^{4}$ Univ. Grenoble Alpes, LGGE, 38041 Grenoble, France \\ ${ }^{5}$ Department of Chemistry, University of Florence, Florence, Italy \\ ${ }^{6}$ Department of Earth Sciences, University of Cambridge, UK \\ *These authors contributed equally to this work.
}

Correspondence to: S. Fujita (sfujita@nipr.ac.jp) and F. Parrenin (parrenin@ujf-grenoble.fr)

Received: 14 January 2015 - Published in Clim. Past Discuss.: 17 February 2015

Revised: 31 August 2015 - Accepted: 29 September 2015 - Published: 19 October 2015

\begin{abstract}
Two deep ice cores, Dome Fuji (DF) and EPICA Dome C (EDC), drilled at remote dome summits in Antarctica, were volcanically synchronized to improve our understanding of their chronologies. Within the past $216 \mathrm{kyr}, 1401$ volcanic tie points have been identified. DFO2006 is the chronology for the DF core that strictly follows $\mathrm{O}_{2} / \mathrm{N}_{2}$ age constraints with interpolation using an ice flow model. AICC2012 is the chronology for five cores, including the EDC core, and is characterized by glaciological approaches combining ice flow modelling with various age markers. A precise comparison between the two chronologies was performed. The age differences between them are within $2 \mathrm{kyr}$, except at Marine Isotope Stage (MIS) 5. DFO2006 gives ages older than AICC2012, with peak values of 4.5 and $3.1 \mathrm{kyr}$ at MIS 5d and MIS 5b, respectively. Accordingly, the ratios of duration (AICC2012 / DFO2006) range between 1.4 at MIS $5 \mathrm{e}$ and 0.7 at MIS 5a. When making a comparison with accurately dated speleothem records, the age of DFO2006 agrees well at MIS 5d, while the age of AICC2012 agrees well at MIS 5b, supporting their accuracy at these stages. In addition, we found that glaciological approaches tend to give chronologies with younger ages and with longer durations than age markers suggest at MIS 5d-6. Therefore, we hypothesize that the causes of the DFO2006-AICC2012 age differences at MIS 5 are (i) overestimation in surface mass balance at around MIS 5d-6 in the glaciological approach and (ii) an error in one of the $\mathrm{O}_{2} / \mathrm{N}_{2}$ age constraints by
\end{abstract}

$\sim 3 \mathrm{kyr}$ at MIS 5b. Overall, we improved our knowledge of the timing and duration of climatic stages at MIS 5. This new understanding will be incorporated into the production of the next common age scale. Additionally, we found that the deuterium signals of ice, $\delta \mathrm{D}_{\text {ice }}$, at $\mathrm{DF}$ tends to lead the one at EDC, with the DF lead being more pronounced during cold periods. The lead of DF is by +710 years (maximum) at MIS $5 \mathrm{~d},-230$ years (minimum) at MIS $7 \mathrm{a}$ and +60 to +126 years on average.

\section{Introduction}

Ice core records are rich archives of climate history over timescales of glacial-interglacial cycles up to $\sim 800 \mathrm{kyr}$ before present (BP; e.g. EPICA Community Members, 2004; Kawamura et al., 2007; Petit et al., 1999). In ice core studies, dating is a central issue that must be investigated in order to better constrain the timing, sequence and duration of past climatic events and stages (e.g. Bazin et al., 2013; Kawamura et al., 2007; Parrenin et al., 2004, 2007a; Veres et al., 2013; Lemieux-Dudon et al., 2010). In addition, good ice core age models are generally important, because ice core chronologies are often used in other types of palaeoclimatic studies. Recently, efforts to establish a common age scale of several Antarctic ice cores (Vostok, EPICA Dome $\mathrm{C}$ (EDC), EPICA Dronning Maud Land (EDML) and Ta- 
los Dome (TALDICE)) have been made (Bazin et al., 2013; Lemieux-Dudon et al., 2010; Veres et al., 2013). The latest common age scale is called the Antarctic Ice Core Chronology 2012 (AICC2012). For the past $60 \mathrm{kyr}$, the age scale was constrained by layer counting of Greenland's ice cores (see Veres et al., 2013). For ice older than $60 \mathrm{kyr}$, dating of Antarctic cores is based on various approaches combining ice flow modelling with orbital tuning age markers and other age markers. Typical orbital tuning markers include the isotopic composition of oxygen (hereinafter $\delta^{18} \mathrm{O}_{\mathrm{atm}}$ ) from air bubbles, total air content (TAC), and the $\mathrm{O}_{2} / \mathrm{N}_{2}$ ratios of occluded air. Typical maximum age uncertainties of these markers are claimed to be $\sim 6, \sim 4$ (Bazin et al., 2013) and $\sim 2$ kyr (Kawamura et al., 2007; Parrenin et al., 2007b; Hutterli et al., 2009), respectively, although some studies suggest that larger errors can occur in some $\mathrm{O}_{2} / \mathrm{N}_{2}$ ratio age markers (e.g. Hutterli et al., 2009; Landais et al., 2012). As a result, age uncertainties depend on the availability and choice of these kinds of age markers for each of the deep ice cores such as EDC (Parrenin et al., 2007a), Vostok (Parrenin et al., 2004; Suwa and Bender, 2008) and DF ice cores (Kawamura et al., 2007; Parrenin et al., 2007a). To better constrain common age scales, synchronization of deep ice cores using common events such as volcanic markers is a very important task.

In ice core studies, electrical conductivity studies are usually performed first because such methods are useful in quickly locating positions of volcanic events. These methods include electrical conductivity measurement (ECM; e.g. Hammer, 1980; Wolff, 2000), dielectric profile (DEP; e.g. Moore and Paren, 1987; Wilhelms et al., 1998) and ACECM (e.g. Fujita et al., 2002c). ACECM is a method to detect the complex admittance between electrodes dragged on the ice surface with a millimetre-scale resolution and at $1 \mathrm{MHz}$ frequency. In addition, fast ion chromatography (FIC) yields continuous records of ions, including sulfate ions (Traversi et al., 2002). Although each of these electrical signals (ECM, DEP and ACECM) and signals from chemical analysis has its own characteristic, they are equally useful in locating acidic spike events in ice cores from the East Antarctic Plateau (see references given for each method above). Fallout of sulfuric acid is known to occur for one or more years following eruptions due to its residence time in the atmosphere (e.g. Gao et al., 2006; Hammer et al., 1980). Volcanic signals found in an Antarctic ice core can originate either from volcanoes located in the middle southern latitudes (e.g. South America and the South Pacific) and the high southern latitudes (the Antarctic continent and the subantarctic islands) or from volcanoes located in the low latitudes of either hemisphere (e.g. ColeDai et al., 2000). Additionally, a low-latitude eruption must be sufficiently explosive to inject volcanic materials directly into the stratosphere in order for its aerosols to be transported to the polar atmosphere and deposited in Antarctic snow (e.g. Cole-Dai et al., 2000). These signals of volcanic events are very useful in synchronizing ice cores. For example, the EDC core has been volcanically synchronized with other major ice cores: with the Vostok ice core by 102 tie points covering $145 \mathrm{kyr}$ BP (Parrenin et al., 2012), with the EDML ice core by $\sim 320$ tie points covering $150 \mathrm{kyr}$ BP (Ruth et al., 2007; Severi et al., 2007), and with the TALDICE core by $\sim 130$ tie points covering $42 \mathrm{kyr}$ BP (Severi et al., 2012). These tie points are used to build a common chronology (Bazin et al., 2013; Veres et al., 2013). We note that Bazin et al. (2013) also used gas stratigraphic links in addition to ice stratigraphic links.

The DF core was drilled at the dome summit in the Dronning Maud Land in East Antarctica, located at $77^{\circ} 19^{\prime} \mathrm{S}$, $39^{\circ} 42^{\prime} \mathrm{E}$ (Fig. 1; Watanabe et al., 1999). The elevation is $3800 \mathrm{~m}$ relative to the WGS84 geoid, and the ice thickness is $3028( \pm 15) \mathrm{m}$ (Fujita et al., 1999). The EDC core was drilled at one of the dome summits located at $75^{\circ} 06^{\prime} \mathrm{S}, 123^{\circ} 21^{\prime} \mathrm{E}$, $\sim 2000 \mathrm{~km}$ away from DF (Fig. 1; EPICA Community Members, 2004). The elevation of EDC is $\sim 570 \mathrm{~m}$ lower than DF at $3233 \mathrm{~m}$ (WGS84), and the ice thickness is $3273( \pm 5) \mathrm{m}$ (Parrenin et al., 2007b). In the published original age scale of the DF core called DFO2006 (Kawamura et al., 2007), there are $23 \mathrm{O}_{2} / \mathrm{N}_{2}$ age markers between $80 \mathrm{kyr} \mathrm{BP}$ and $340 \mathrm{kyr}$ BP. These $\mathrm{O}_{2} / \mathrm{N}_{2}$ constraints were interpolated by ice flow modelling. Therefore, synchronization between the DF core and the EDC core means that the chronology strictly constrained by the $\mathrm{O}_{2} / \mathrm{N}_{2}$ age markers of the DF core can be compared with AICC2012, the chronology for five cores including the EDC core, and characterized by glaciological approaches combining ice flow modelling with various age markers (Bazin et al., 2013; Veres et al., 2013). In the AICC2012 chronology, for the period of the past $216 \mathrm{kyr}$ studied in this paper, ice age markers of TAC and the $\mathrm{O}_{2} / \mathrm{N}_{2}$ ratio were used from the EDC core and the Vostok core, respectively. In addition, gas age markers of $\delta^{18} \mathrm{O}_{\text {atm }}$ have been used from the EDC, Vostok and TALDICE cores. These gas age markers were linked to the age of ice through assumptions of firn thickness and the lock-in depths of air. Note here that gas is trapped in polar ice sheets at $50-120 \mathrm{~m}$ below the surface, and the gas age is therefore younger than the age of the surrounding ice (ice age). Based on the DF-EDC synchronization in this paper, a precise comparison between the two age scales (DFO2006 and AICC2012) can be made, which is a major step toward improving our understanding of the chronology of Antarctic ice cores for the period over the past $216 \mathrm{kyr}$.

\section{Methods}

\subsection{Data sets}

At each of the two sites described above, two deep ice cores have been drilled. At DF, the first core (DF1 core) was recovered during the period 1992-1998 to a depth of $2503 \mathrm{~m}$ (Watanabe et al., 2003). The second $3035 \mathrm{~m}$ long core (DF2 core), reaching nearly to the ice sheet bed, was drilled in the period 2004-2007 at a site $\sim 43 \mathrm{~m}$ away from the DF1 


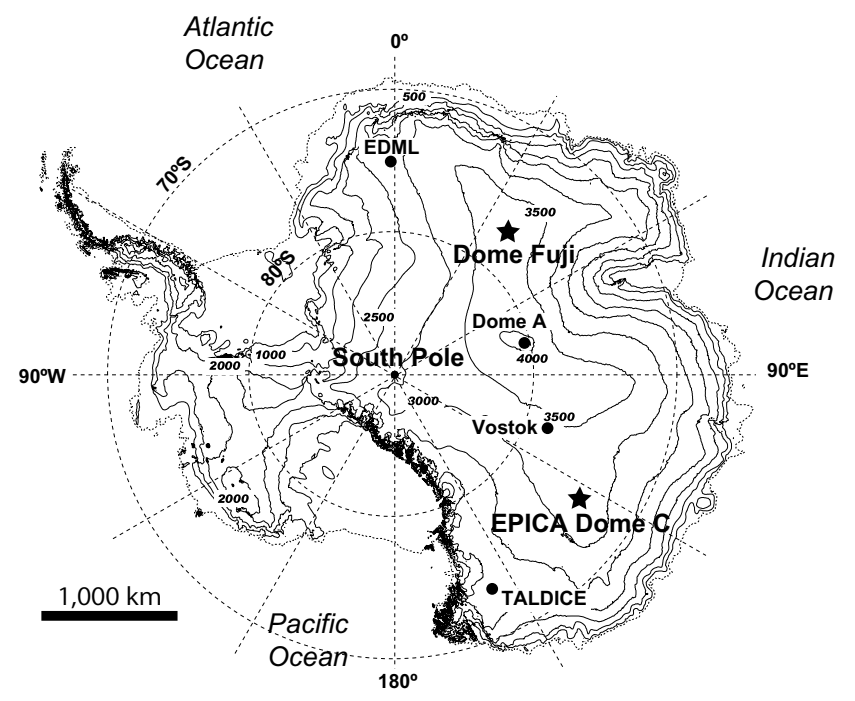

Figure 1. Map of the continent of Antarctica with elevation contours every $500 \mathrm{~m}$. The two ice coring sites used in this study, Dome $\mathrm{C}$ and Dome Fuji, are marked with stars.

borehole (Motoyama, 2007). At EDC, the first core (EDC96 core) was started in the 1996/1997 season to a depth down to $790 \mathrm{~m}$. The second $3270 \mathrm{~m}$ long core (EDC99 core), reaching nearly to the ice sheet bed, was started during the 1999/2000 season at a site $10 \mathrm{~m}$ away from the EDC96 core (EPICA Community Members, 2004). Ice core signals from these four cores were used in the synchronization work in this study. From these ice cores, we used data profiles indicative of strong acids originated from large volcanic eruptions (see Table 1). Resolutions are from 1 to $4 \mathrm{~cm}$. For all these cores, depth determinations were based on the widely used method of logging of ice cores (e.g. Fujita et al., 2002a).

\subsection{Method of synchronization}

First, by using depth-profile graphs of the data sets described above and comparing between them, major tie points were extracted manually. Typically, we attempted to extract a tie point within at least each $5 \mathrm{~m}$ of depth, although this was not always possible. In glacial periods, there is often a lack of convincing tie points - presumably because of the frequent loss/disturbance of annual layers due to reworking of the snow surface by wind scouring under lower accumulation rate conditions and possible accumulation hiatuses, which remove the distinct volcanic layers. At an initial stage, $\sim 650$ tie points were extracted down to a depth of $\sim 2180 \mathrm{~m}$ for both cores, using prominent peaks common between ice core signals from different ice cores. The $\sim 650$ tie points were found as patterns of appearance in ice core signals versus depth and they provided initial hints to recognize further matching patterns of tie points. This method of detection using pattern matching made us confident about identifying the candidate tie points. There are more possible tie points deeper down, but they require more careful examination due to the smoothing of signals by the diffusion of acid peaks (e.g. Barnes et al., 2003; Fujita et al., 2002c), and this work is out of the scope of the present study. Second, a semi-automatic computer-aided synchronization interface was constructed (see Fig. A1 in Appendix A). Based on the initial $\sim 650$ major tie points, as many plausible minor tie point peaks as possible were extracted using the interface. A final determination was made by an operator who evaluated patterns of matching by careful observation of the shape, size and synchronicity of the candidate peaks. Using the PC interface, 1401 tie points, including the original $\sim 650$ points, were extracted. We note that, even for cores at the same site (such as EDC96 and EDC99, DF1 and DF2), there are variable relative depth offsets caused by borehole inclinations, cumulative small errors of ice core logging, fractures, postcoring relaxations of the core and surface snow redeposition processes such as sastrugi. Thanks to a successful synchronization, the offsets were also extracted (data not shown) to avoid any complexity caused by the variable relative depth offsets between cores at the same dome sites. For the EDC core, we converted all depths into depths equivalent to the DEP data of the EDC99 core because these data cover the longest continuous depth span at EDC. We also converted all the DF2 depths into equivalent depths of the DF1 core. The amplitudes of the peak signals were highly variable due to spatially and temporally heterogeneous depositional conditions by winds on the surface of the ice sheet (Barnes et al., 2006; Kameda et al., 2008; Wolff et al., 2005). However, synchronization was always conducted by finding patterns of peaks regardless of peak height. When the patterns of data fluctuations (locations of multiple peaks of signals in terms of relative depth) agreed between two or more sets of data at DF and EDC, they were extracted as tie points with confidence even if some peaks in the pattern matching were small. When we synchronized volcanically between the EDC core and the DF core, the ECM data of the Vostok ice core (Parrenin et al., 2012) were also synchronized at the same time (see the graph of Vostok ECM data in the interface in Fig. A1). Between DF and Vostok, and between EDC and Vostok, for each pair of ice cores, we identified more than 800 tie points covering the past $140 \mathrm{kyr}$. The simultaneous nature of the synchronization for the three deep ice cores provided an opportunity for cross-checks (triple check of the pattern among DF, EDC and Vostok), and we were able to identify tie points confidently. Assessment of the confidence associated with the 1401 tie points is given in Appendix B of this paper. In Fig. 2, we provide an example of a set of extracted tie points over a depth span of approximately $20 \mathrm{~m}$. In addition, in Supplement A, we provide 80 sets of graphs showing all records of the synchronization covering the past $216 \mathrm{kyr}$. In this paper, the Vostok data are not developed in order to focus our discussions on the relations between the two dome sites at DF and EDC. We also note that tephra matches were not used in the synchronization work, because tephra 
Table 1. Summary of data sets of ice core signals used for synchronization.

\begin{tabular}{|c|c|c|c|c|c|c|}
\hline Core & $\begin{array}{l}\text { Name of } \\
\text { measurement }\end{array}$ & $\begin{array}{r}\text { Depth range } \\
\text { used }(\mathrm{m})\end{array}$ & Measured properties & $\begin{array}{r}\text { Measurement } \\
\text { temperature }\left({ }^{\circ} \mathrm{C}\right)\end{array}$ & $\begin{array}{r}\text { Depth } \\
\text { resolution }(\mathrm{cm})\end{array}$ & Reference \\
\hline \multirow[t]{2}{*}{$\mathrm{DF} 1$} & $\mathrm{ECM}$ & $2-2250$ & Direct current of solid ice & -20 to -30 & 1 & Fujita et al. $(2002 a, b, c)$ \\
\hline & AC-ECM & $112-250$ & High-frequency conductance of solid ice at $1 \mathrm{MHz}$ & -20 to -30 & 1 & Fujita et al. (2002a, b, c) \\
\hline \multirow[t]{2}{*}{ DF2 } & ECM & $889-2250$ & Direct current of solid ice & -20 & 1 & This study \\
\hline & AC-ECM & $889-2250$ & High-frequency conductance of solid ice at $1 \mathrm{MHz}$ & -20 & 1 & This study \\
\hline \multirow[t]{3}{*}{ EDC96 } & ECM & $99-788$ & Direct current of solid ice & -20 & 1 & EPICA Community Members (2004) \\
\hline & Sulfate & $7-788$ & Concentration of sulfate ions & & 4 & Udisti et al. (2000) \\
\hline & DEP & $7-788$ & High-frequency conductivity of solid ice at $100 \mathrm{kHz}$ & -20 & 2 & Wolff et al. (2005) \\
\hline \multirow[t]{3}{*}{ EDC99 } & ECM & $772-3188$ & Direct current of solid ice & -20 & 1 & EPICA Community Members (2004) \\
\hline & Sulfate & 769-2094 & Concentration of sulfate ions & & 2 & Udisti et al. (2004) \\
\hline & DEP & $7-3165$ & High-frequency conductivity of solid ice at $100 \mathrm{kHz}$ & -20 & 2 & Wolff et al. (2005) \\
\hline
\end{tabular}

layers that originated from the same source (eruptions) were rare among deep ice cores from East Antarctica (see Narcisi et al., 2005). In this paper, instead of using tephra matches in the synchronization work, we used them as posterior tests of the synchronization work.

\section{Results}

\subsection{Features of the tie points}

The EDC-DF volcanic matching consists of 1401 depth tie points (Fig. 2 and all records of synchronization in the Supplement A). Data are distributed heterogeneously in time (Fig. 3). In Fig. 3, depths of the tie points in each ice core are plotted versus time using a single common age scale. In the present case, we use the DFO2006 scale at the bottom axis with the AICC2012 scale at the top axis as a reference. In Fig. 3, the variations in the slope on the profiles are due to variable surface mass balance (SMB) and thinning effects after deposition. For the periods of MIS 3 and 5, a relatively large number of tie points were found, typically 10-20 points over every $1 \mathrm{kyr}$ interval (Fig. 3 bottom). The variations in the number of tie points are due to the variable number of major volcanic eruptions, variable atmospheric circulation, variable depositional environment such as SMB, possible signal diffusion effects in ice after deposition, and variable number of data sets available for the synchronization work. It became harder to find tie points in the deeper part of the cores, in particular in some cold periods such as MIS 6 (see Fig. 3). This was presumably because of the frequent occurrence of periods of very low surface accumulation or accumulation hiatuses during MIS 6 and additional effects from diffusion of sulfuric acid in ice.

We note that the previous interglacial period (i.e. 120$130 \mathrm{kyr} \mathrm{BP}$ ) has about twice the number of match points as the Holocene (i.e. 0-10 kyr BP). Because the availability of data sets depends on depth range (see Table 1), the number of tie points for each time span does not simply reflect the occurrence frequency of large volcanic eruptions. From the ice sheet surface to a depth close to $900 \mathrm{~m}$, no data set from the DF2 core was available for synchronization. We deduce that this situation limited the number of identified tie points; we generally find more tie points when we have more sets of ice core data to look at.

\subsection{Difference between the age scales DFO2006 and AICC2012}

From these 1401 tie points, we can calculate the difference in age scales of the DF core and the EDC core (DF-EDC). The differences in age scales are given in Fig. 4a. We find that for the periods of MIS $1-4,6$ and $7 \mathrm{a}$, the difference ranges between 0 and $-2.0 \mathrm{kyr}$. In the period of MIS 5 , the difference ranges between 0 and $+4.5 \mathrm{kyr}$. The fact that the DFO2006 chronology is older than the AICC2012 chronology at the last interglacial had already been observed by Bazin et al. (2013; see their Fig. 7), and we confirmed this conclusion based on precise synchronization. A remarkable feature is that the age difference has peak values of +4.5 and $+3.1 \mathrm{kyr}$ at MIS 5d and MIS 5b, respectively. Before MIS 5d and after MIS $5 \mathrm{~b}$, differences decrease from the peak values, but cover the entire MIS 5 and the late stage of MIS 6 (age younger than $\sim 150 \mathrm{kyr} \mathrm{BP}$ ).

\subsection{Difference in durations between DFO2006 and AICC2012 age scales}

We also investigated the difference in durations of various timescales between DFO2006 and AICC2012. In Fig. 4a, the variable slope of the red profiles is related to the ratio of duration on DFO2006 and AICC2012. A positive (negative) slope from the past toward present means longer (shorter) durations on AICC2012 compared to those on DFO2006. In Fig. 4b, ratios of duration (in this paper called the duration ratio) between AICC2012 and DFO2006 ages are calculated by dividing durations in AICC2012 by durations in DFO2006 at each interval of the 1401 tie points. A smoothed line (50point smoothing of the raw data; dots) shows the mean tendency. The duration ratio has large fluctuations. The smallest value (0.7) and largest value (1.4) are found at MIS 5a and MIS 5e, respectively. The duration ratio is relatively stable between the Holocene and MIS 4 (94.2 kyr BP) with a $\sigma$ (standard deviation) value of 0.08 . Between MIS 5 and the late stage of MIS 6 (from 150 to $94.2 \mathrm{kyr} \mathrm{BP}$ ), $\sigma$ is 0.18 . Be- 


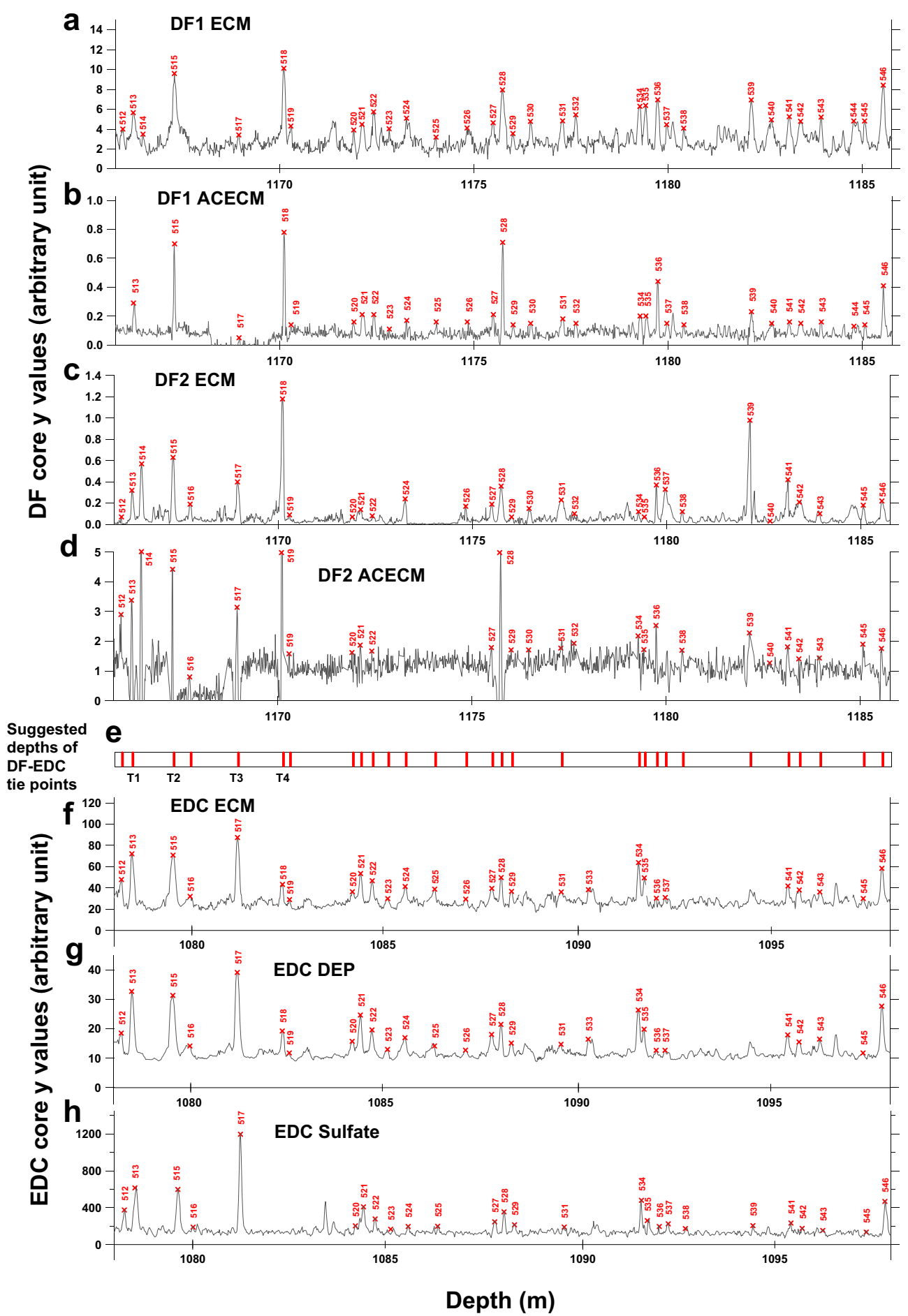

Figure 2. An example of a set of extracted tie points over a depth span of approximately $20 \mathrm{~m}$ in both the DF and EDC cores. Graphs, from top to bottom, are for (a) DF1 ECM, (b) DF1 ACECM, (c) DF2 ECM, (d) DF2 ACECM, (e) suggested depths of tie points, (f) EDC DEP, (g) EDC ECM and (h) EDC sulfate (see Table 1). Scales of the $y$ axes for the ECM, DEP and ACECM graphs are all arbitrary. Red markers with ID numbers (from 512 to 546) are spikes that were extracted using the PC interface (see Appendix A1). The presence of the same ID numbers in multiple graphs means that the spikes were identified as events from the same timings, that is, from the same origins of volcanic eruptions. The ID numbers are used only for the working purpose of synchronization. This set of examples contains a plausible Toba super-eruption that occurred sometime at $\sim 74 \mathrm{kyr}$ BP, studied by Svensson et al. (2013). Tie points with ID numbers $513,515,517$ and 518 (shown as letters T1-T4 in e) were discussed by Svensson et al. (2012; see their Fig. 8) as tie points of the Toba super-eruption. All data covering $216 \mathrm{kyr}$ are shown in the Supplement. 


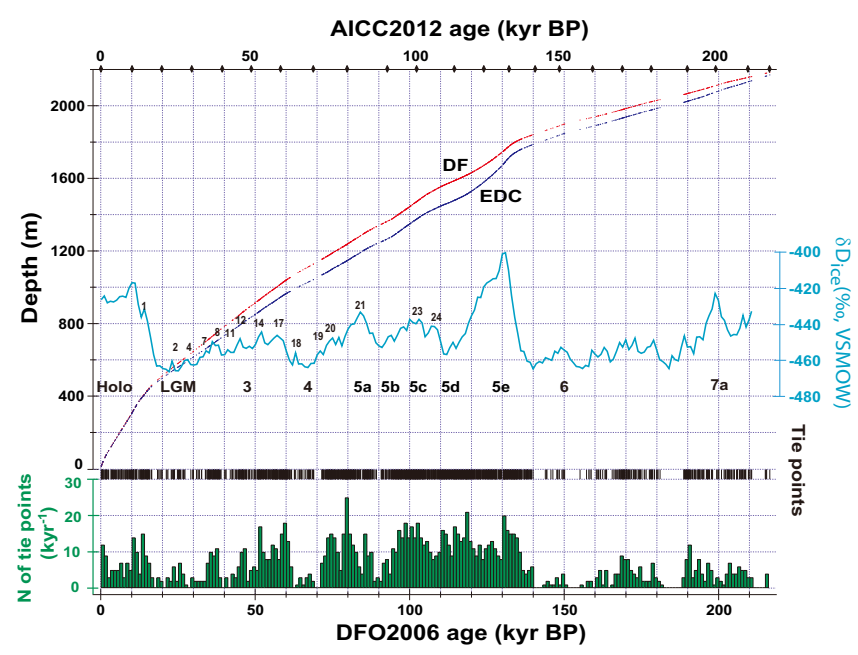

Figure 3. Result of volcanic synchronization: DF depth-EDC depth on a tentative common age scale DFO2006 (bottom axis). AICC2012 scale is also given on the top axis as a reference. Blue trace with indications of the marine isotope stages and Antarctic isotope maxima (AIM) is $\delta \mathrm{D}_{\text {ice }}$ of DF core averaged over every $1 \mathrm{kyr}$ for reference (Uemura et al., 2012). Black vertical markers are locations of the tie points on the age scale. The green histogram shows the number of tie points found over every $1 \mathrm{kyr}$ interval.

tween 216 and $150 \mathrm{kyr}$ BP, $\sigma$ is 0.10 . Clearly, fluctuation of the duration ratio is large between MIS 5 and the late stage of MIS 6.

In addition, the duration ratio between intervals defined by the $\mathrm{O}_{2} / \mathrm{N}_{2}$ age markers (Table 3), which occur on precessional (9-14 kyr) timescales, was examined. In intervals of the precessional cycles of the $\mathrm{O}_{2} / \mathrm{N}_{2}$ age markers, the difference in durations ranges approximately within $\pm 3 \mathrm{kyr}$. As a result, the duration ratio ranges between 0.75 and 1.25.

\section{Discussion}

We first describe what may potentially cause the age differences. After that, phasing between the deuterium records of ice, $\delta \mathrm{D}_{\text {ice }}(\%$, VSMOW), is described. We also examine compatibility between several examples of the tephra matches and the matches of the volcanic marker (acidic) peaks. The age scale for the DF core, DFO2006, is an interpolation between the $\mathrm{O}_{2} / \mathrm{N}_{2}$ age constraints using glaciological ice flow modelling (Kawamura et al., 2007). In contrast, the age scale AICC2012 is the best compromise between a background chronology (based on modelling of the SMB, snow densification into ice and ice flow) and observations (absolute ages or certain reference horizons, and stratigraphic links among several cores and orbital ages; Bazin et al., 2013). AICC2012 is more a "glaciological chronology" than DFO2006 is because it gives more weight to the glaciological sedimentation models. Therefore, the age differences between the two chronologies are caused by both dating ap- proaches and the complex effects from elements used in the dating approaches. To understand the age differences, we should consider (i) errors in age constraints, (ii) SMB errors, (iii) errors in estimation of ice thinning, (iv) possible propagation of the errors through stratigraphic links, and (v) effects from differences in the dating approaches.

\subsection{Examination of chronologies in terms of age markers}

\subsubsection{Comparison of the DFO2006-AICC2012 ages with the ages of the absolutely dated speleothem records from China}

In order to examine possible causes of the DFO2006AICC2012 age differences, DFO2006 and AICC2012 ages are compared with the ages of the absolutely dated speleothem records from China (hereinafter referred to as speleo-age; Cheng et al., 2009) based on synchronization between the EDC core record and the Chinese speleothem records (Barker et al., 2011) and on the DF-EDC volcanic synchronization. The ages of speleothems from Sanbao Cave were determined using the ${ }^{230} \mathrm{Th}$ dating technique by Cheng et al. (2009). Speleothem synchronization makes the assumption that rapid changes in speleothem $\delta^{18} \mathrm{O}$ are synchronous with rapid changes in the temperatures in Greenland, which were in turn deduced as the break points in the slope of the Antarctic $\delta \mathrm{D}_{\text {ice }}$ record. Details of the comparison are given in Fig. 4d. At MIS 1-5a, 5e and 6, both chronologies (DFO2006 and AICC2012) are within $2 \mathrm{kyr}$ of the speleo-age. At MIS $5 \mathrm{~b}$, the speleo-age and the AICC2012 ages agree quite well, whereas only the DFO2006 age deviates by up to $3 \mathrm{kyr}$. In contrast, at MIS 5d, the speleo-age and the DFO2006 ages agree quite well, whereas only the AICC2012 age deviates by up to $4 \mathrm{kyr}$. At MIS 7a, the DFO2006 and the AICC2012 ages agree well, whereas only the speleo-age deviates by up to $4 \mathrm{kyr}$. However, the features used to match the speleothem with the EDC $\delta \mathrm{D}_{\text {ice }}$ at this depth are ambiguous, so it is possible that the matching process at this depth is in error. In summary, based on the comparison with the ages of the absolutely dated speleothem records, we suggest the following.

i. Except at MIS 5b and MIS 7a, the DFO2006 chronology is supported by the absolutely dated speleothem records from China. At MIS 5b, DFO2006, one of the $\mathrm{O}_{2} / \mathrm{N}_{2}$ age markers with the ID F4 at $94.2( \pm 1.4) \mathrm{kyr}$ $\mathrm{BP}$ (on DFO2006), deviates from the speleothem ages by about $3 \mathrm{kyr}$ toward the older direction. On the other hand, in the interval 0-100 kyr BP, the AICC2012 and speleothem ages agree very well. Thus, from this comparison, it is very likely that one of the $\mathrm{O}_{2} / \mathrm{N}_{2}$ age markers at $94.2,( \pm 1.4) \mathrm{kyr} \mathrm{BP}$ at MIS $5 \mathrm{~b}$ is a major source of error.

ii. Except at MIS 5d and MIS 7a, the AICC2012 chronology is supported by the speleothem records. At MIS 
AlCC2012 age (kyr BP)
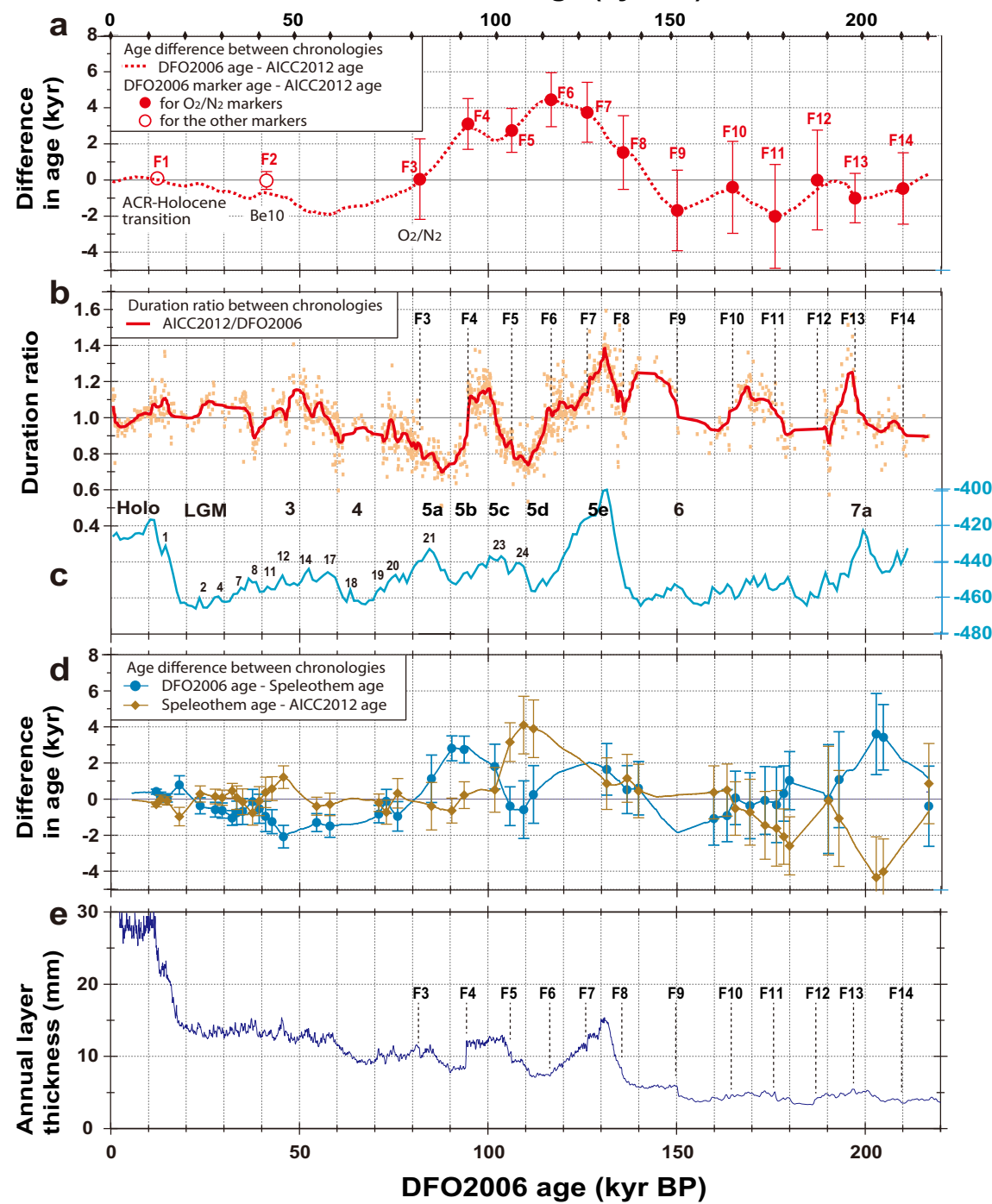

Figure 4. Comparison between DFO2006 age and AICC2012 age plotted on a common age scale. We use the DFO2006 scale at the bottom axis with the AICC2012 scale at the top axis. For all these figures, details are given in the main text. (a) Age difference between the two chronologies [DFO2006 age - AICC2012 age] (red dotted line). In addition, this age difference is compared with the age difference [DFO2006 marker age - AICC2012 age]. Information of the DFO2006 marker age is from Table 2. (b) Ratios of durations (duration ratio) between AICC2012 ages and DFO2006 ages are calculated as duration on AICC2012 divided by duration on DFO2006 at each interval of the 1401 tie points. A smoothed line with 50-point smoothing of the raw data (dots) shows the mean tendency. Again, ages of the $\mathrm{O}_{2} / \mathrm{N}_{2}$ age markers (Table 3) are shown. (c) Blue trace with indications of the marine isotope stages (MIS) and Antarctic Isotope Maxima (AIM) is $\delta \mathrm{D}_{\text {ice }}$ of DF core averaged over every $1 \mathrm{kyr}$ for reference (Uemura et al., 2012). (d) DFO2006 and AICC2012 ages are compared with the ages of the Chinese speleothem age (speleo-age) (Cheng et al., 2009) based on a link of the EDC core record to the Chinese speleothem records (Barker et al., 2011). The age differences [DFO2006 age - speleo-age] (blue line) and the age differences [speleo-age - AICC2012 age] (yellow line) are given. Note that a reason for not subtracting speleo from both is to make comparison between Fig. $4 \mathrm{a}$ and $\mathrm{d}$ easier at MIS 5. Solid symbol markers (both circles and diamonds) with indicated uncertainty are from tie points between the EDC core record and the speleothem records (Table S1 in Barker et al., 2011). (e) Thickness of annual layers in the Dome Fuji ice core was calculated on DFO2006 chronology. Ages of the $\mathrm{O}_{2} / \mathrm{N}_{2}$ age markers (listed in Table 2) are shown. We can observe a step in the annual layer thickness at the age marker at $94.2 \mathrm{kyr}$ BP (ID: F4).

5d, AICC2012 deviates from the speleothem ages by about $4 \mathrm{kyr}$ toward the younger direction. On the other hand, at MIS 5d, the DFO2006 and speleothem ages agree very well. Thus, it is very likely that an error in AICC2012 age at MIS 5d is a major source of the DFO2006-AICC2012 age differences. 
Table 2. Depths and AICC2012 ages of EDC core at depth/age of age markers of DF core.

\begin{tabular}{|c|c|c|c|c|c|c|c|}
\hline \multirow[b]{2}{*}{ ID } & \multirow[b]{2}{*}{ Type } & \multicolumn{3}{|c|}{ DF core ${ }^{a}$} & \multicolumn{2}{|l|}{ EDC core ${ }^{b}$} & \multirow{2}{*}{$\begin{array}{r}\text { Age } \\
\text { difference } \\
\text { A-B } \\
(\mathrm{yr})\end{array}$} \\
\hline & & $\begin{array}{r}\text { Depth of } \\
\text { DF1 core } \\
(\mathrm{m})\end{array}$ & $\begin{array}{l}\text { Age of age } \\
\text { marker (A) } \\
\quad(\mathrm{yr} b 2 \mathrm{k})\end{array}$ & $\begin{array}{r}2 \sigma \text { of } \\
\text { age marker } \\
(\mathrm{yr})\end{array}$ & $\begin{array}{r}\text { Synchronized depth } \\
\text { on EDC99 core } \\
\text { (m) }\end{array}$ & $\begin{array}{r}\text { Age on AICC2012 } \\
\text { chronology (B) } \\
(\mathrm{yr} b 2 \mathrm{k})\end{array}$ & \\
\hline $\mathrm{F} 1$ & ACR-Holocene & 371.00 & 12390 & 200 & 371.46 & 12296 & 94 \\
\hline $\mathrm{F} 2$ & Be10 peak & 791.00 & 41205 & 500 & 739.35 & 41227 & -22 \\
\hline F3 & $\mathrm{O}_{2} / \mathrm{N}_{2}$ & 1261.55 & 81973 & 2230 & 1170.17 & 81923 & 50 \\
\hline $\mathrm{F} 4$ & $\mathrm{O}_{2} / \mathrm{N}_{2}$ & 1375.69 & 94240 & 1410 & 1278.73 & 91132 & 3108 \\
\hline F5 & $\mathrm{O}_{2} / \mathrm{N}_{2}$ & 1518.87 & 106263 & 1220 & 1417.10 & 103518 & 2745 \\
\hline F6 & $\mathrm{O}_{2} / \mathrm{N}_{2}$ & 1605.26 & 116891 & 1490 & 1498.03 & 112443 & 4448 \\
\hline F7 & $\mathrm{O}_{2} / \mathrm{N}_{2}$ & 1699.14 & 126469 & 1660 & 1614.13 & 122718 & 3751 \\
\hline F8 & $\mathrm{O}_{2} / \mathrm{N}_{2}$ & 1824.78 & 137359 & 2040 & 1769.25 & 135839 & 1520 \\
\hline F9 & $\mathrm{O}_{2} / \mathrm{N}_{2}$ & 1900.68 & 150368 & 2230 & 1849.02 & 152058 & -1690 \\
\hline F10 & $\mathrm{O}_{2} / \mathrm{N}_{2}$ & 1958.32 & 164412 & 2550 & 1910.13 & 164814 & -402 \\
\hline F11 & $\mathrm{O}_{2} / \mathrm{N}_{2}$ & 2015.00 & 176353 & 2880 & 1969.00 & 178365 & -2012 \\
\hline F12 & $\mathrm{O}_{2} / \mathrm{N}_{2}$ & 2052.25 & 186470 & 2770 & 2008.59 & 186471 & -1 \\
\hline F13 & $\mathrm{O}_{2} / \mathrm{N}_{2}$ & 2103.11 & 197394 & 1370 & 2066.08 & 198399 & -1005 \\
\hline F14 & $\mathrm{O}_{2} / \mathrm{N}_{2}$ & 2156.64 & 209523 & 1980 & 2131.85 & 209998 & -475 \\
\hline
\end{tabular}

${ }^{a}$ Age markers of DF core is from Kawamura et al. (2007). ${ }^{b}$ AICC2012 chronology is from Bazin et al. (2013).

iii. At MIS 7a, only the absolute speleothem age deviates. This may suggest that an incorrect matching between the speleothem and ice core rapid changes has been made.

In addition, we find another feature of the DFO2006 chronology to support the belief that the $94.2( \pm 1.4) \mathrm{kyr}$ BP age at MIS $5 \mathrm{~b}$ is in error. In Fig. 4e, we show the thicknesses of annual layers in the ice sheet, calculated from a relation between depth and age. We find a sharp step of the annual layer thickness at $94.2 \mathrm{kyr}$ BP. Such a step needs anomalous flow if this result is real. We note that annual layer thickness does not have such a step at $94.2 \mathrm{kyr}$ BP on the AICC2012 chronology. We also note that we still find a few other such steps at F9 and F12. However, these steps are very small compared to the step at F4. From the step at F4, we deduce that the step will become smaller if we shift the $94.2 \mathrm{kyr}$ BP age constraint toward the younger direction. This agrees with the possible $3 \mathrm{kyr}$ error toward the older direction identified by comparison with the speleothem records.

Moreover, in Fig. 4b, the duration ratio has a sharp step at $94.2 \mathrm{kyr} \mathrm{BP}$, suggesting that the age constraints with the $\sim 3 \mathrm{kyr}$ error caused a bias to the duration ratio; before (after) the $94.2 \mathrm{kyr}$ BP age constraint, the ratio is larger (smaller) because of the smaller (larger) denominator in the AICC2012/DFO2006 duration ratio. Thus, the duration ratios at intervals F3-F4 and F4-F5 are affected by the $\sim 3 \mathrm{kyr}$ error.

\subsubsection{Cross-checks between the DFO2006-AICC2012 chronologies and their age markers}

To understand the possible error of $-4 \mathrm{kyr}$ (where negative means an error toward the younger direction) of the AICC2012 age at around MIS 5d, we perform cross-checks between the two chronologies (AICC2012 and DFO2006) and the age markers used in building these two chronologies. We calculate [DFO2006 marker ages - AICC2012 age] and [DFO2006 age - AICC2012 marker ages], and then we observe the results at around MIS 5d. The calculated results are shown as marker symbols in Figs. 4a and 5a, respectively, and also given in Tables 2 and 4, respectively. Here, we examine only ice ages of the markers (such as TAC markers, $\mathrm{O}_{2} / \mathrm{N}_{2}$ age markers and some other ice age markers such as ${ }^{10} \mathrm{Be}$, Antarctic Cold Reversal-Holocene transition and volcanic tephra) and ice ages of the chronology in order to avoid complications in the analysis introduced by gas age markers or gas age links. Note that there is a difference between the ice age of a marker and the ice age of a chronology in cases of glaciological chronology such as AICC2012. In Fig. 4a, the data points are on the red dotted line of the DFO2006AICC2012 age difference, because DFO2006 is strictly constrained by the age markers. In Fig. 4a, the ID at each data point is the ID of each age marker in Table 2. Error bars are $2 \sigma$ confidence intervals of the age markers (Table 2). We have already discussed the most likely error of the $94.2 \mathrm{kyr}$ BP marker at F4, and so we exclude this marker from our discussion here. We find that the DFO2006-AICC2012 age differences violate the $2 \sigma$ confidence intervals at points with IDs F5, F6 and F7. Therefore, in terms of the $\mathrm{O}_{2} / \mathrm{N}_{2}$ age 


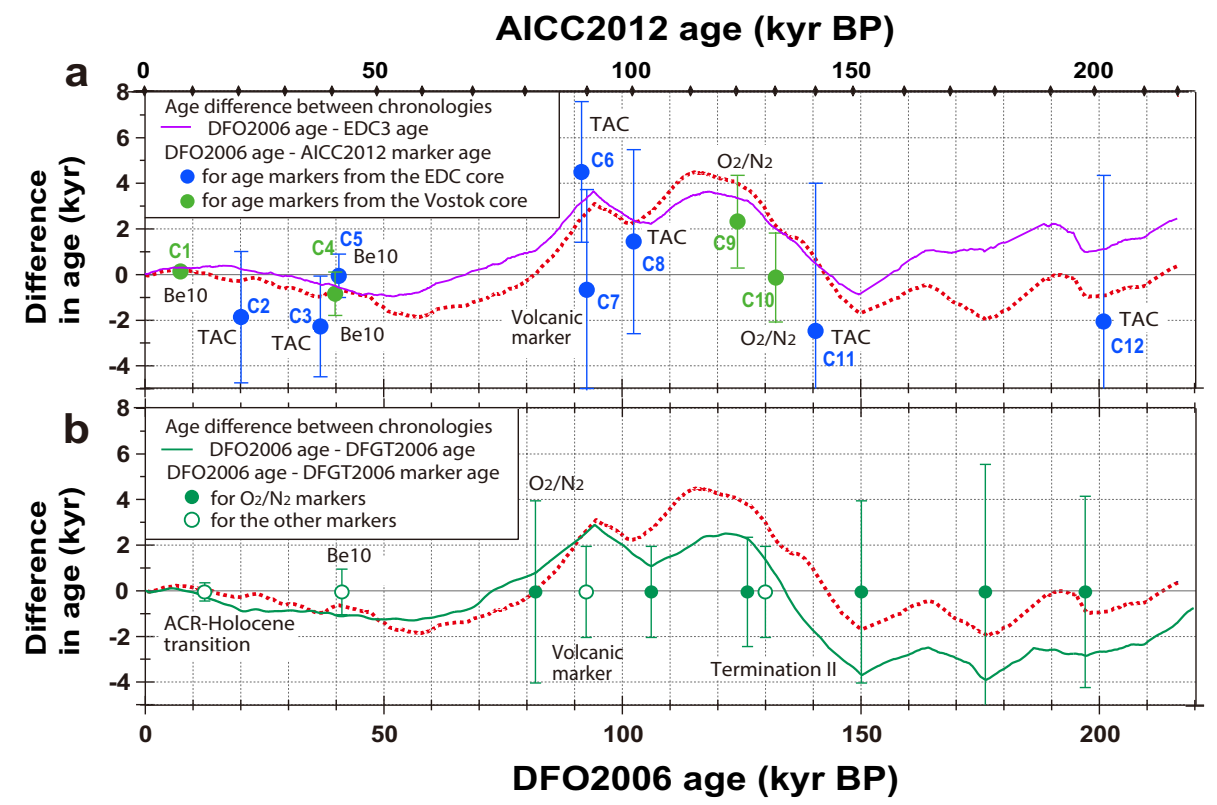

Figure 5. Comparisons between DFO2006 age and AICC2012 age are plotted on a common age scale. Again, as in Fig. 4, we use the DFO2006 scale at the bottom axis with the AICC2012 scale at the top axis. (a) The age difference between the two chronologies [DFO2006 age - AICC2012 age] (red dotted line reproduced from Fig. 4a) is compared with age difference [DFO2006 age - AICC2012 marker age]. Information of the AICC2012 age markers is from Table 4. The age difference [DFO2006 age - EDC3 age] is shown as a purple line. (b) DFO2006 age, the $\mathrm{O}_{2} / \mathrm{N}_{2}$ chronology of the DF core is compared with "DFGT2006", the glaciological chronology of the same DF core. It is shown as [DFO2006 age - DFGT2006 age] (green line in the figure). Although the age markers of the two chronologies have no age differences, DFGT2006 uses a smaller number of markers and has a larger uncertainty setting to less constrain the age by the age markers. We observe that the green line and [DFO2006 age - AICC2012 age] (red dotted line reproduced from Fig. 4a) have similar variations with peak differences at MIS $5 \mathrm{~b}$ and $5 \mathrm{~d}$.

constraints, the AICC2012 chronology at MIS 5d is out of the acceptable range.

In Fig. 5a, the data points are not on the DFO2006AICC2012 age difference (red dotted line) because AICC2012 is a glaciological timescale. In Fig. 5a, the number at each data point is the ID of each age marker in Table 4. Blue symbols and green symbols are for age markers from the EDC core and the Vostok core, respectively (Bazin et al., 2013). The $\mathrm{O}_{2} / \mathrm{N}_{2}$ age markers with IDs $\mathrm{C} 9$ and $\mathrm{C} 10$ are from the Vostok core, originally published by Suwa and Bender (2008). Bazin et al. (2013) attributed $4 \mathrm{kyr}$ as the $2 \sigma$ confidence intervals of these $\mathrm{O}_{2} / \mathrm{N}_{2}$ age markers instead of the 2 kyr intervals originally assessed by Suwa and Bender (2008). Bazin et al. (2013) used conservative values of the uncertainty because of their questions about the phasing of the local insolation curve and $\mathrm{O}_{2} / \mathrm{N}_{2}$ curve. However, we use here the $2 \mathrm{kyr}$ intervals given by the original authors. This choice is supported partly by the fact that the DFO2006 chronology agrees well with the absolutely dated speleothem records from China except at MIS 5b and MIS 7a. We find here that the DFO2006-AICC2012 age differences nearly violate the $2 \sigma$ confidence intervals of the $\mathrm{O}_{2} / \mathrm{N}_{2}$ constraints at points $\mathrm{C} 9$ and C10; again, in terms of the $\mathrm{O}_{2} / \mathrm{N}_{2}$ age con- straints, AICC2012 chronology at MIS 5d is out of the acceptable range.

A remarkable feature in Fig. 5a is that in periods of MIS 5c, 5d and 5e, the DFO2006-AICC2012 age differences (red dotted line) are systematically larger than values of [DFO2006 age - AICC2012 marker age] by 1-3 kyr. Thus, the 1-3 kyr differences are apparently not driven by the age incompatibility between the ice age markers used for establishing the two chronologies. Below we examine the remaining possibilities.

\subsection{Possible causes of the DFO2006-AICC2012 age differences at around MIS 5d}

\subsubsection{Possible effects of ice thinning}

One of the possibilities for the age difference at MIS $5 \mathrm{~d}$ is errors in the estimation of vertical thinning in glaciological modelling in AICC2012. However, we find no glaciological explanation that, at the two coring sites of DF and EDC, errors in the estimation of vertical thinning occur only at MIS $5 \mathrm{~d}$. In addition, according to the concept of conservation of mass, a thinner layer at one location can only be explained if this layer is thicker in a neighbouring location. However, no such example is seen in the isochronal layers observed 
Table 3. Duration between $\mathrm{O}_{2} / \mathrm{N}_{2}$ time markers on two different timescales and their differences and ratio.

\begin{tabular}{|c|c|c|c|c|c|c|}
\hline \multirow[b]{2}{*}{ ID } & \multicolumn{2}{|c|}{$\begin{array}{c}\text { Age on the } \mathrm{DF} \mathrm{O}_{2} / \mathrm{N}_{2} \\
\text { time marker }\end{array}$} & \multicolumn{2}{|c|}{ Duration } & \multirow{2}{*}{$\begin{array}{r}\text { Difference } \\
\text { in duration } \\
\text { D-C } \\
(\mathrm{yr})\end{array}$} & \multirow{2}{*}{$\begin{array}{r}\text { Duration ratio } \\
\mathrm{D} / \mathrm{C}\end{array}$} \\
\hline & $\begin{array}{r}\text { Start } \\
(\mathrm{yr} b 2 \mathrm{k})\end{array}$ & $\begin{array}{r}\text { End } \\
(\mathrm{yr} b 2 \mathrm{k})\end{array}$ & $\begin{array}{r}\text { On the } \mathrm{DF} \mathrm{O}_{2} / \mathrm{N}_{2} \\
\text { time marker }(\mathrm{C}) \\
(\mathrm{yr})\end{array}$ & $\begin{array}{r}\text { On the AICC2012 } \\
\text { age scale (D) } \\
(\mathrm{yr})\end{array}$ & & \\
\hline F3-F4 & 81973.3 & 94239.8 & 12267 & 9209 & -3058 & 0.75 \\
\hline F4-F5 & 94239.8 & 106263 & 12023 & 12387 & 363 & 1.03 \\
\hline F5-F6 & 106263 & 116891 & 10628 & 8925 & -1703 & 0.84 \\
\hline F6-F7 & 116891 & 126469 & 9578 & 10275 & 697 & 1.07 \\
\hline F7-F8 & 126469 & 137359 & 10890 & 13121 & 2231 & 1.20 \\
\hline F8-F9 & 137359 & 150368 & 13009 & 16219 & 3210 & 1.25 \\
\hline F9-F10 & 150368 & 164412 & 14044 & 12756 & -1288 & 0.91 \\
\hline F10-F11 & 164412 & 176353 & 11941 & 13551 & 1610 & 1.13 \\
\hline $\mathrm{F} 11-\mathrm{F} 12$ & 176353 & 186470 & 10117 & 8106 & -2011 & 0.80 \\
\hline F12-F13 & 186470 & 197394 & 10924 & 11928 & 1004 & 1.09 \\
\hline F13-F14 & 197394 & 209523 & 12129 & 11599 & -530 & 0.96 \\
\hline
\end{tabular}

by radio echo sounding. We can see the isochronal layers at Dome Fuji (Fujita et al., 1999, 2012; Steinhage et al., 2013) and those at Dome C (Cavitte et al., 2013; Tabacco et al., 1998).

\subsubsection{Influence by links from other cores}

We consider a possibility of complex effects of the other ice core orbital markers and numerous stratigraphic links with the influence of background scenarios. Bazin et al. (2013) used numerous gas age markers of $\delta^{18} \mathrm{O}_{\text {atm }}$ from the Vostok core and the TALDICE core for periods covering MIS 5. These numerous gas age makers are linked with the ice age of the AICC2012 through assumptions of firn thicknesses at each site and lock-in depths. However, there is a circumstantial evidence that raises the possibility of influence by links from other cores. The previous age scale of the EDC core is known as EDC3 (Parrenin et al., 2007a). EDC3 is the glaciological chronology based on the use of a set of independent age markers as well as the SMB and mechanical flow modelling. Bazin et al. (2013) showed that the timing and duration of MIS 5 in AICC2012 is basically unchanged compared to EDC3. We performed analysis of the DFO2006-EDC3 age difference in the same way as the analysis of the DFO2006-AICC2012 age difference. We found that the basic profile of the DFO2006-EDC3 age difference is similar to the DFO2006-AICC2012 age difference (purple line in Fig. 5a). Again, we find a peak value of $+3.6 \mathrm{kyr}$ at MIS 5d. Because the EDC3 age scale is independent of any stratigraphic links to other ice cores, appearance of this peak value means that influence by links from other cores introduced to the AICC2012 gave no major effects to the observed features of the age differences. In addition, according to Bazin et al. (2013), the ice age difference between the $\mathrm{O}_{2} / \mathrm{N}_{2}$ chronology and the $\delta^{18} \mathrm{O}_{\text {atm }}$ chronology on the Vos- tok ice has no anomalous biases that occur particularly at periods around MIS 5 (see Fig. 4 in Bazin et al., 2013). We therefore exclude this possibility as well.

\subsubsection{Influence of surface mass balance}

We are interested in the remaining possibility - errors in estimating SMB at around MIS 5d in the glaciological flow modelling. To examine this possibility, we introduce a comparison between DFO2006 chronology with the glaciological chronology of the same DF core, DFGT2006 (Parrenin et al., 2007a) in Fig. 5b. DFGT2006 is a timescale based on a sedimentation model, with sedimentation parameters being constrained using some dated horizon. It is not strictly constrained to dated horizons, as DFO2006 is. In Fig. 5b, we find that the DFO2006-DFGT2006 age difference has a peak of difference at $5 \mathrm{~d}$, very similar to both the variation of the DFO2006-AICC2012 age difference (Fig. 4a) and that of the DFO2006-EDC3 age difference (Fig. 5a). Based on this similarity, we hypothesize that the DFO2006-AICC2012 age difference at MIS $5 \mathrm{~d}$ is mostly related to a difference in dating approaches, between the $\mathrm{O}_{2} / \mathrm{N}_{2}$ age-marker-based dating and the glaciological dating. We argue that the most plausible cause is the error in estimation of SMB.

The large difference between the DFO2006 and glaciological chronologies (such as AICC2012, EDC3 and DFGT2006) at MIS 5d is explained by an overestimation of the SMB as compared to true SMB values at each site in a period from the late stage of MIS 6 until MIS 5d in all the glaciological chronologies. If this overestimation occurs, ice around MIS 5d will have a systematic bias causing younger ages. Consequently, the duration of a period from the late stage of MIS 6 until MIS 5d will have a systematic bias causing longer intervals. 
Table 4. Depths and DFO2006 ages of DF core at depth/age of age markers of AICC2012 chronology.

\begin{tabular}{|c|c|c|c|c|c|c|c|c|}
\hline \multirow[b]{2}{*}{ ID } & \multirow[b]{2}{*}{ Type } & \multicolumn{4}{|c|}{ Age markers used to constrain AICC2012 age scale } & \multicolumn{2}{|c|}{ Age on DFO2006 chronology } & \multirow{2}{*}{$\begin{array}{r}\text { Age difference } \\
\text { F-E } \\
(\mathrm{yr})\end{array}$} \\
\hline & & $\begin{array}{l}\text { Original } \\
\text { core }\end{array}$ & $\begin{array}{r}\text { Depth in } \\
\text { original core } \\
(\mathrm{m})\end{array}$ & $\begin{array}{l}\text { Age of age } \\
\text { marker }(E) \\
\quad(y r b 2 k)\end{array}$ & $\begin{array}{r}2 \sigma \text { of } \\
\text { time marker } \\
(\mathrm{yr})\end{array}$ & $\begin{array}{r}\text { Synchronized } \\
\text { depth on DF1 core } \\
(\mathrm{m})\end{array}$ & $\begin{array}{r}\text { Age on DFO2006 } \\
\text { chronology }(\mathrm{F}) \\
(\mathrm{yr} b 2 \mathrm{k})\end{array}$ & \\
\hline $\mathrm{C} 1$ & Be10 & Vostok & 178.00 & 7230 & 100 & 233.27 & 7372 & 142 \\
\hline $\mathrm{C} 2$ & TAC & EDC & 501.65 & 22000 & 2879 & 514.14 & 20132 & -1868 \\
\hline $\mathrm{C} 3$ & TAC & EDC & 693.67 & 39000 & 2211 & 738.20 & 36732 & -2268 \\
\hline $\mathrm{C} 4$ & Be10 & Vostok & 601.00 & 40700 & 950 & 781.66 & 39864 & -836 \\
\hline C5 & $\mathrm{Be} 10$ & EDC & 740.08 & 40700 & 950 & 791.81 & 40642 & -58 \\
\hline C6 & TAC & EDC & 1255.93 & 87000 & 3082 & 1352.73 & 91495 & 4495 \\
\hline $\mathrm{C} 7$ & Mt Berlin tephra & EDC & 1265.10 & 93250 & 4400 & 1361.74 & 92580 & -670 \\
\hline $\mathrm{C} 8$ & TAC & EDC & 1377.67 & 101000 & 4031 & 1473.94 & 102438 & 1438 \\
\hline $\mathrm{C} 9$ & $\mathrm{O}_{2} / \mathrm{N}_{2}$ & Vostok & 1675.00 & 121850 & 4000 & 1673.08 & 124172 & 2322 \\
\hline $\mathrm{C} 10$ & $\mathrm{O}_{2} / \mathrm{N}_{2}$ & Vostok & 1853.70 & 132350 & 4000 & 1777.84 & 132221 & -129 \\
\hline $\mathrm{C} 11$ & TAC & EDC & 1790.29 & 143000 & 6468 & 1843.81 & 140540 & -2460 \\
\hline $\mathrm{C} 12$ & TAC & EDC & 2086.69 & 203000 & 6403 & 2121.00 & 200939 & -2061 \\
\hline
\end{tabular}

\subsection{Phasing between $216 \mathrm{kyr}$ long $\delta \mathrm{D}_{\text {ice }}$ records at Dome Fuji and Dome C}

In this section, we discuss phasing between the $216 \mathrm{kyr}$ long $\delta \mathrm{D}_{\text {ice }}$ records in the DF and EDC cores. Our intention is to investigate possible differences in timing in the $\delta \mathrm{D}_{\text {ice }}$ records from the two remote dome sites in East Antarctica. $\delta \mathrm{D}_{\text {ice }}$ records at DF and EDC are from Uemura et al. (2012) and Jouzel et al. (2007), respectively. In Fig. 6, they are plotted against common chronologies, again DFO2006 on the bottom axis and AICC2012 on the top axis. Each of the three graphs shows an age span of $75 \mathrm{kyr}$. From look at the phasing closely it is apparent that there are stages where there are differences in graph shapes. A remarkable feature is that, over a period of approximately $20 \mathrm{kyr}$ at MIS $5 \mathrm{~d}-5 \mathrm{e}$, the decrease in the $\delta \mathrm{D}_{\text {ice }}$ record at DF leads the decrease in the $\delta \mathrm{D}_{\text {ice }}$ record of the EDC (see Fig. 6b). Another noticeable feature is that EDC signals seem to lead at $\sim 200 \mathrm{kyr}$ BP. In order to see the average phasing over the $216 \mathrm{kyr}$, the correlation coefficient of the $\delta \mathrm{D}_{\text {ice }}$ records, shifted by $x$ years, was calculated. The result is shown in Fig. 7. The correlation coefficient has a maximum when DF leads by 60 years. However, we observe that the peak in this graph has an asymmetric shape; the left side slope is steeper than the right side slope. If we consider this asymmetry, the actual centre of this peak (as a result of peak fittings) is +126 years. To investigate this feature more closely and as a function of time, the correlation coefficient of the $\delta \mathrm{D}_{\text {ice }}$ records, shifted by $x$ years, was calculated on 20000 -year time windows. The calculation was repeated at every 10000 years. In Fig. 8, the maximum of correlation on each 20000-year time window is given. It is remarkable in this graph that the lead of DF is between $\sim+710$ years at $120 \mathrm{kyr}$ BP (at MIS 5d) and -230 years at $200 \mathrm{kyr}$ BP (at MIS 7a). On average, the lead of DF is +98 years. This averaged lead ( +98 years) is consistent to the lead of the peak value ( +60 years) and to the actual peak centre $(+126$ years). These features are very interesting. But they open many questions as to causes of the time-dependent phasing. We observe some systematic features: (i) peaks of the DF lead tend to appear over colder periods ( $180 \mathrm{kyr}$ BP at the beginning of MIS 6, $120 \mathrm{kyr}$ BP at MIS 5d and 60-80 kyr BP at MIS 4); (ii) the lead of DF is weak at some cold periods such as the Last Glacial Maximum, end of MIS 6 and so on; (iii) the lead of DF is very weak, or the lead of EDC appears several times during warm periods, at the Holocene, MIS 5a-5b, MIS 5e and MIS 7a.

We argue that the observed features above are not caused by errors in synchronization as it is very unlikely that our pattern matching caused a systematic shift in synchronization. Even if some points were mismatched within the pattern matching, such errors would be random, and they would cancel each other out in the correlation analysis. We argue that the appearance of the phase shift is real. If we assume that most of the millennial-scale changes are following the bipolar seesaw pattern, then the Southern Ocean signal likely has a delay in it (WAIS Divide Project Members, 2015) compared to the Northern Hemisphere signal. It seems plausible that the delay is a little less in the Atlantic compared to the Indian and Pacific sectors. We therefore suggest that an average delay as small as +60 to +126 years can occur naturally. In future studies, we clearly need further exploration of the time-dependent variations in the phasing. This topic requires comprehensive discussions combining knowledge of palaeoclimatic records, climate dynamics and ice sheet dynamics, which is beyond the scope of this paper.

\subsection{Comparison with stratigraphic links of visible ash layers}

Using the geochemical analysis of visible ash layers in the two cores, Narcisi et al. (2005) proposed stratigraphic links between DF and EDC at four depths within the past $216 \mathrm{kyr}$. This was based partly on tephra stratigraphic links between 

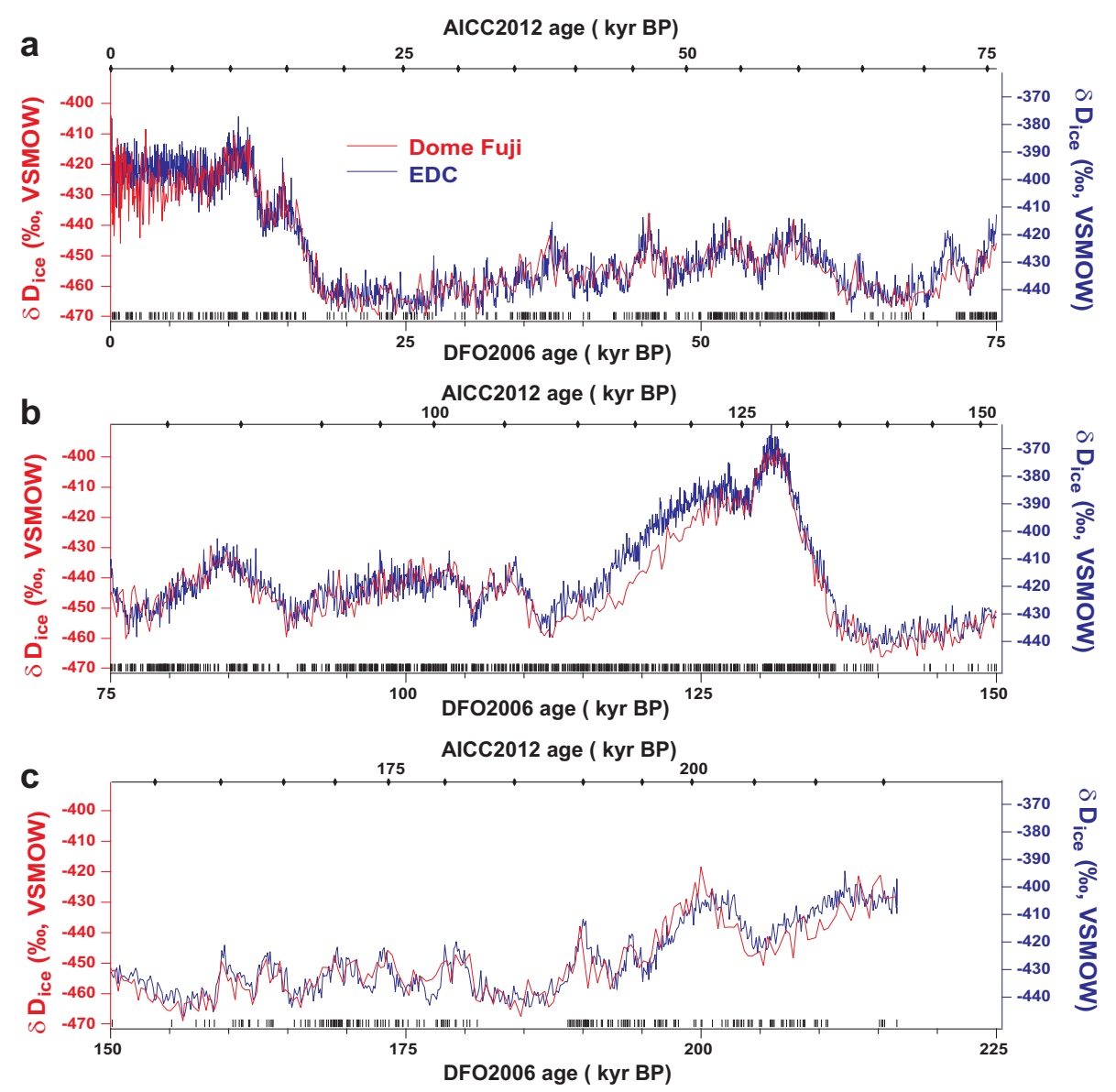

Figure 6. In order to observe phasing between $\delta \mathrm{D}_{\text {ice }}$ records at the DF and EDC ice cores, these isotopic records are plotted versus common chronologies, again tentatively DFO2006 on the bottom axis and AICC2012 on the top axis. Each of the three graphs shows an age span of $75 \mathrm{kyr}$. At the bottom of each graph, the timing of the 1401 tie points is shown.

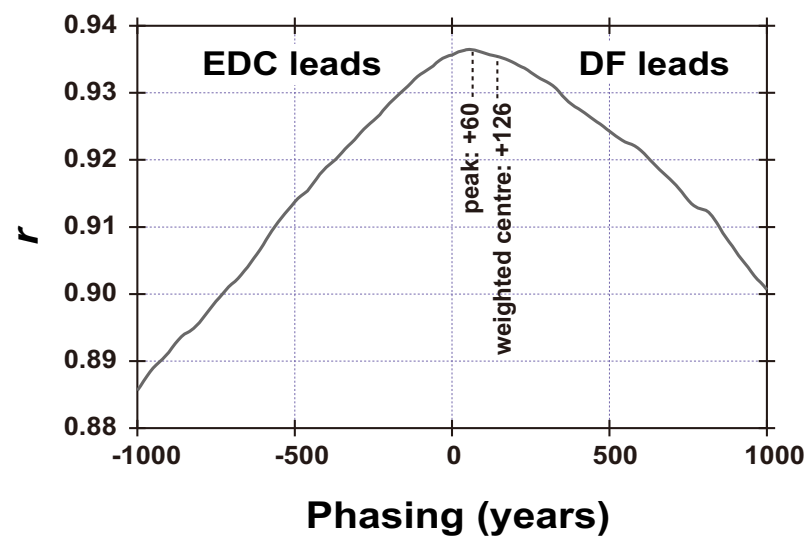

Figure 7. In order to see the average phasing over the $216 \mathrm{kyr}$, the correlation coefficient ( $r$ in the left axis) of the $\delta \mathrm{D}_{\text {ice }}$ records, shifted by $x$ years (bottom axis), was calculated. $r$ has a peak value when DF leads by +60 years. Considering the asymmetry of the peak shape, the weighted centre was calculated to be +126 years.
DF and Vostok that had been proposed earlier (Kohno et al., 2004). We confirm that three of the links (DF 1361.89-EDC 1265.1 m, DF 1849.55-EDC 1796.3 m, DF 2170.18-EDC $2150.9 \mathrm{~m}$ ) are consistent with the matches we have made using the pattern of volcanic marker peaks in this study; deviation of these links from the track of the DF-EDC volcanic match links is within $0.08 \mathrm{~m}$. Thus, these three links independently support the matches we have proposed at these depths. The fourth one (DF 2117.75-EDC 2086.6 m) is not consistent with our synchronization; deviation of this link from the track of the DF-EDC volcanic match links is approximately $2 \mathrm{~m}$. In addition, we were unable to find a plausibly consistent match if we insisted on this tephra stratigraphic link. In fact, Narcisi et al. (2005) specifically questioned the reality of the link at this depth between DF on the one hand and EDC and Vostok on the other, because the similarity between the geochemical signature was not as high as expected for tephras with an identical source. Our study therefore supports this suspicion, and we suggest that the tephra at DF $(2117.75 \mathrm{~m})$ and EDC $(2086.6 \mathrm{~m})$ are of different ages. Most likely the DF-Vostok link at this depth is also incorrect. This 


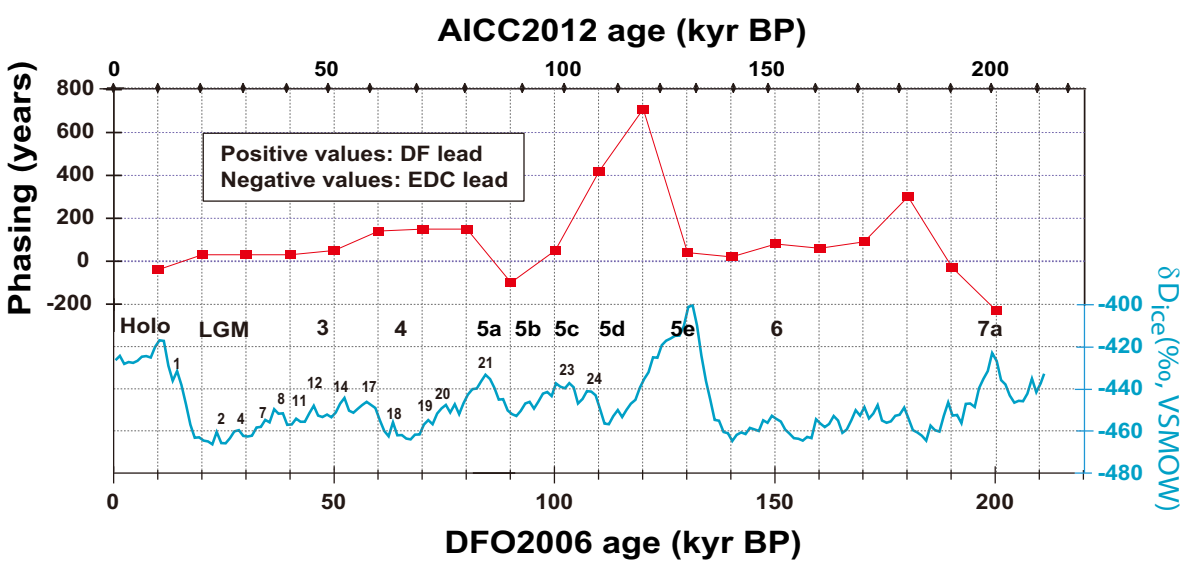

Figure 8. To investigate features of the phasing between the $\delta \mathrm{D}_{\text {ice }}$ records as a function of time, the correlation coefficient of the $\delta \mathrm{D}_{\text {ice }}$ records, shifted by $x$ years, was calculated on 20000 -year time windows. The calculation was repeated for every 10000 years. The maximums of correlation on each 20000 -year time window are given with red marker symbols and lines. Positive and negative values mean lead of DF and EDC, respectively. Blue trace with indications of the marine isotope stages and Antarctic isotope maxima (AIM) is $\delta D_{\text {ice }}$ of $D F$ core averaged over every $1 \mathrm{kyr}$ for reference (Uemura et al., 2012).

highlights the danger of using even partly geochemically fingerprinted stratigraphic matches of single layers in isolation, especially across the continent, where it will be unusual for tephras transported in the troposphere to be recorded simultaneously at such distant sites as EDC and DF.

\section{Concluding remarks and future prospects}

Based on the DF-EDC synchronization with the 1401 tie points, a precise comparison between several important age models was carried out. The models include DFO2006, AICC2012, EDC3, DFGT2006 and ages of the speleothem records from China. This comparison between various chronologies brought us new insights into the chronologies of deep ice cores as well as the relationship between climatic records from the two sites. Important results are summarized as follows.

i. Two very deep ice cores in East Antarctica drilled at Dome Fuji and Dome $\mathrm{C}$ were precisely synchronized in the ice phase using 1401 tie points for a very long period covering the last $216 \mathrm{kyr}$.

ii. Now and in the future, analyses of ice core records over $216 \mathrm{kyr}$ can be conducted precisely on a common age scale, either AICC2012, DFO2006 or an improved age model combining both cores.

iii. For a long period of the latest $100 \mathrm{kyr}$, the AICC2012 chronology compares well with the speleothem age, suggesting that AICC2012 is the most reliable age model for this time interval.

iv. At MIS 5d, 5e and 6, the DFO2006 chronology compares well with the speleothem age, suggesting that DFO2006 is reliable in this time interval. v. At MIS 7a, even the ages inferred from the absolutely dated speleothem records from China may have errors as large as $4 \mathrm{kyr}$, a matter that should be further investigated. This may suggest that an incorrect matching between the speleothem and ice core rapid changes has been made.

vi. Duration ratio (AICC2012/DFO2006) ranges between 0.7 at MIS 5a and 1.4 at MIS 5e. Fluctuations are large at MIS 5. The fluctuation in the duration ratio is clearly caused by the complex effects of the errors in the two chronologies. Thus, we must be very careful in estimations of durations in climate modelling and flux studies where correct values of durations are very important.

vii. One of the $\mathrm{O}_{2} / \mathrm{N}_{2}$ age markers in the DF core at $94.2 \mathrm{kyr}$ BP probably has an error of $3 \mathrm{kyr}$ toward the older direction, which should be further investigated by additional ice core measurements of $\mathrm{O}_{2} / \mathrm{N}_{2}$.

viii. At MIS 5d, 5e and late stage of 6 , the glaciological approach of the age models is very likely to have suffered from errors in estimation of surface mass balance.

ix. Analysis for the phasing between $\delta \mathrm{D}_{\text {ice }}$ records at $\mathrm{DF}$ and EDC was performed. We found that the $\delta \mathrm{D}_{\text {ice }}$ signals at DF tends to lead the one at EDC, with the DF lead being more pronounced during cold periods. The lead of DF is by +710 years (maximum) at MIS $5 \mathrm{~d},-230$ years (minimum) at MIS $7 \mathrm{a}$ and +60 to +126 years on average. The phase delay was attributed to a north-to-south directionality of the abrupt climatic signal, which is propagated from the Northern Hemisphere to the Southern Hemisphere high latitudes by oceanic rather than atmospheric processes (WAIS Divide Project Members, 2015). It seems plausible that 
the delay is a little less in the Atlantic compared to the Indian and Pacific sectors. This topic of the phasing requires comprehensive discussions combining knowledge of palaeoclimatic records, climate dynamics and ice sheet dynamics. Clearly, we need further exploration of both the time-dependent variations in the phasing and the spatial distribution of them. As a method of the future investigation, analysis of phasing among several major Antarctic deep ice cores, such as DF, EDC, EDML, Talos Dome, Vostok and WAIS cores, will be effective and necessary. Then, detailed volcanic synchronization works among these ice cores, like this study, will be a basis.

$x$. The reliability of the synchronization was based on a matching of patterns. During some cold periods, such a matching of patterns was impossible. For such periods, we need additional information to find correlations between volcanic peak signals. In addition, this lack of matching patterns may provide us with information on depositional environments in the past.

xi. A comparison between four proposed tephra stratigraphic links and the volcanic marker peaks highlights the danger of using even partly geochemically fingerprinted stratigraphic matches of single layers in isolation.
Finally, the reliability of the orbital age markers such as $\mathrm{O}_{2} / \mathrm{N}_{2}$ age markers and ages of the speleothem records is a key factor that influences the reliability of age models. The TAC age markers are another important set of ice age markers that are free from assumptions of firn thickness and the lock-in depths of air. The reliability of the $\mathrm{O}_{2} / \mathrm{N}_{2}$ age markers and the TAC age markers has been investigated by many researchers (e.g. Bender, 2002; Fujita et al., 2009, 2014; Hutterli et al., 2009; Kawamura et al., 2004, 2007; Landais et al., 2012; Lipenkov et al., 2011; Raynaud et al., 2007; Suwa and Bender, 2008; Hörhold et al., 2012; Courville et al., 2007). It is beyond the scope of this paper to delve into this, but it seems clear that we need to better understand the physical processes in firn determining variations in both $\mathrm{O}_{2} / \mathrm{N}_{2}$ and air content. The new stratigraphic constraint established in this study will be incorporated into the next synchronized and optimized age scale of polar ice cores. 


\section{Appendix A: PC interface to extract tie points}

Here we explain the PC interface used to search for tie points. Based on preliminary tie points, a detailed search can be conducted easily. Figure A1 shows the interface window. The procedures are given below. (The code of the interface is provided as a Supplement (C) in this paper.)

i. Preparation of data files. Each set of ice core data (ECM, DEP, ACECM or sulfate) should have a column of its original depth, data values and tentative depth equivalent to a single reference core (DF1 core in the case of this study). Data on tentative depth equivalent to a single reference core must be collected prior to the use of the PC interface.

ii. Loading of data. All the data should be loaded in the program.

iii. Display graphs on PC interface. We should display a depth-dependent profile of each set of data in a PC window. As in the example shown in Fig. A1, multiple windows should be aligned vertically, so that we can compare the features of each data set easily. Importantly, for the $x$ axis, the tentative depth equivalent to a single reference core must be used in order that the user can easily examine synchronicity between multiple sets of data. In the windows, data should be scalable both in the depth $(x)$ directions and the data value $(y)$ directions. In addition, the $x$ axis should be adjustable for offset of the depth scales for each core data.

iv. Extraction of local maxima from each set of data. In the data profiles, the candidates for tie points should be found by extracting local maxima (dots in the centre of graphs in Fig. 2). Importantly, the operator should be careful to maintain synchronization between graphs by adjusting the offset, otherwise it would be very difficult to find a matching pattern, and observing the pattern of the appearance of peaks is very important.

v. The operator should decide whether to select a datum or not ( $1 / 0$ switches in the right side of the image, in case of this study) by clicking "Record" on the right, the data - depth of peak, peak height and background level - should be recorded only for chosen data.

vi. By shifting the depth range of windows, the operator should search for further tie point candidates. 


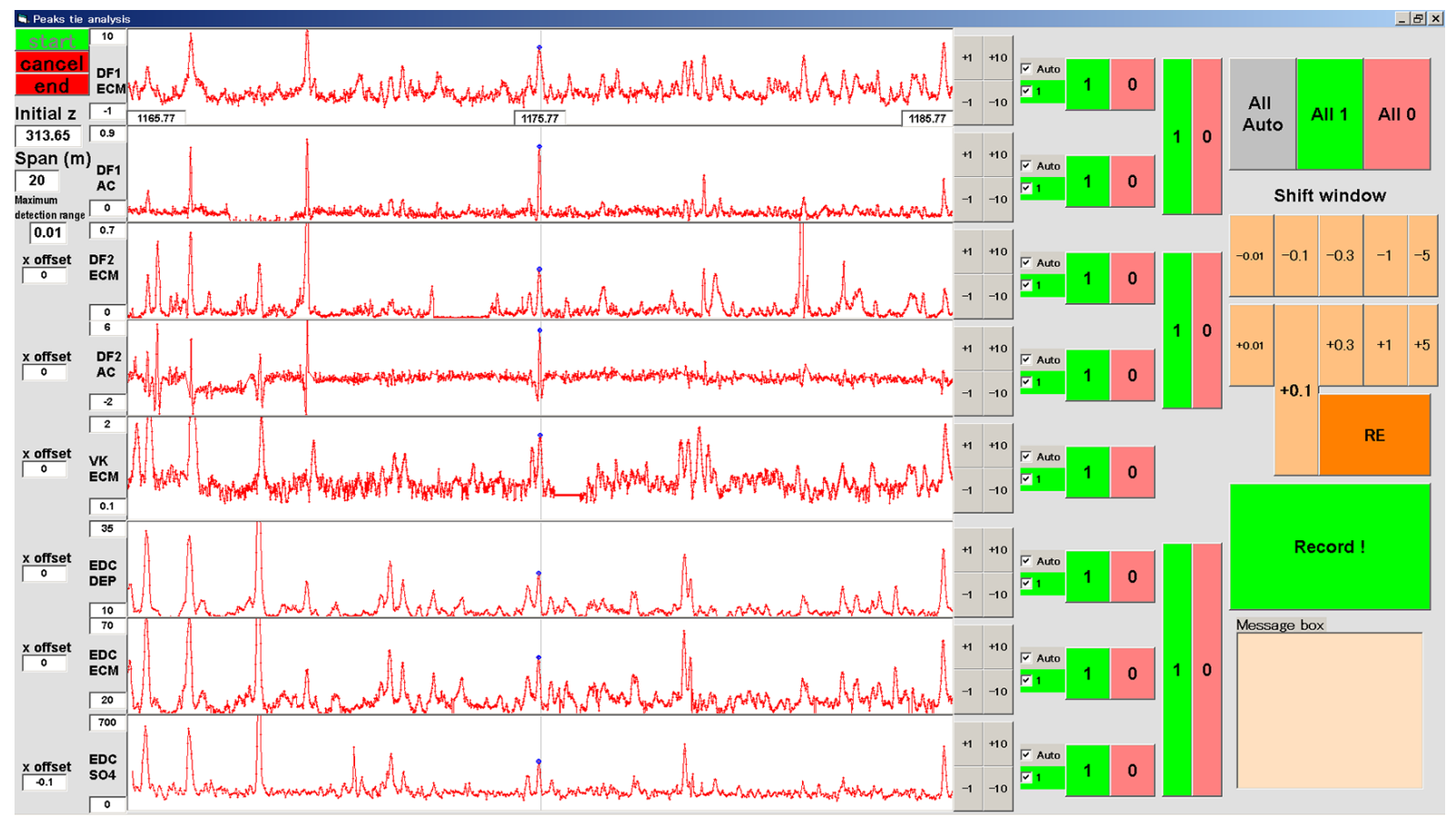

Figure A1. A PC interface window used to search for tie points semi-automatically. Based on preliminary tie points, a detailed search can be conducted easily. In the data profiles (red traces), the candidates for tie points were found by extracting local maxima (dots in the centres of graphs). After choosing each datum or not (1/0 switches in the right side of the image), by clicking "Record" on the right, the data - depth of peak, peak height and background level - are recorded. This example is the same depth window as Fig. 2. The horizontal axis is a depth of approximately $20 \mathrm{~m}$ for both ice cores. Graphs from the top are DF1 ECM, DF1 ACECM, DF2 ECM, DF2 ACECM, Vostok ECM, EDC DEP, EDC ECM and EDC sulfate (see Table 1). 


\section{Appendix B: Confidence level of the tie points}

We examine occurrence probability for choosing wrong tie points in the DF-EDC volcanic synchronization. As we described in the main text, our synchronization work was based on evaluation of pattern matching by careful observation of the shape, size and synchronicity of the candidate peaks. We describe here as to how accidental errors can rarely happen within the pattern matching. The sequence of the 1401 tie points are distributed on a smooth profile in Fig. B1. The 1401 DF-EDC tie points were within time span of the past $216 \mathrm{kyr}$. Thus, the average time span from one tie point to another is $\sim 154$ years although the tie points are distributed irregularly along time. Along the sequence of the irregularly distributed tie points, deviation of each tie point from an interpolated track of the surrounding tie points is in most cases within $0.1 \mathrm{~m}$, as we discuss below. As the volcanic signal frequency in our proxy records is as rare as every $\sim 154$ years (on average), the probability for the accidental appearance of confusing volcanic signals within depths of $\sim 0.1 \mathrm{~m}$ between two cores is very slight.

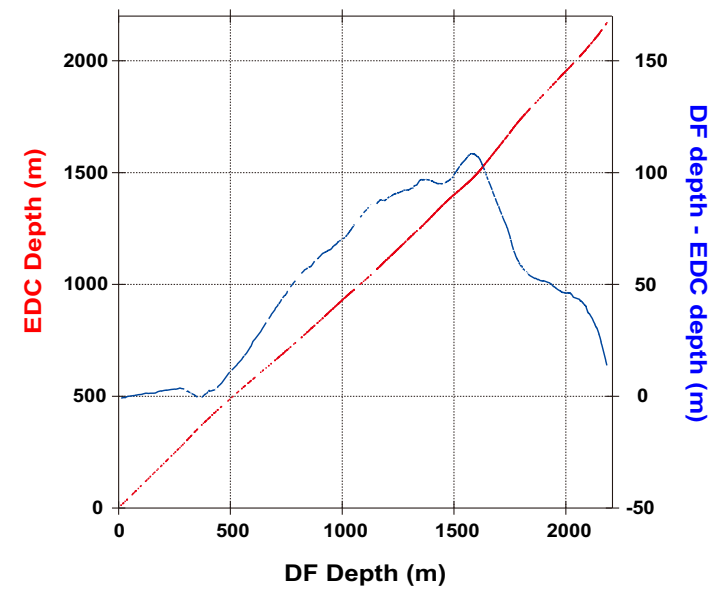

Figure B1. Result of the volcanic synchronization: DF depth-EDC depth diagram (red) and DF depth-EDC depth difference (blue).

Conditions for choosing the wrong tie points by an operator of the PC interface are schematically shown in Fig. B2. Our discussion here is for each single peak within matched patterns.

i. The volcanic signal 1 in the DF core and the volcanic signal 2 in the EDC core must be significantly observable.

ii. At the same time, the volcanic signal 1 in the EDC core and the volcanic signal 2 in the DF core must be faint or absent so as to induce misjudgement of an observer.

iii. These two peaks should be within depths of $\sim 0.1 \mathrm{~m}$ or so of the location expected, assuming the layer thickness ratio between the adjacent volcanic match pairs remains constant. Otherwise, it is highly probable that the

\section{DF core $\quad$ EDC core}

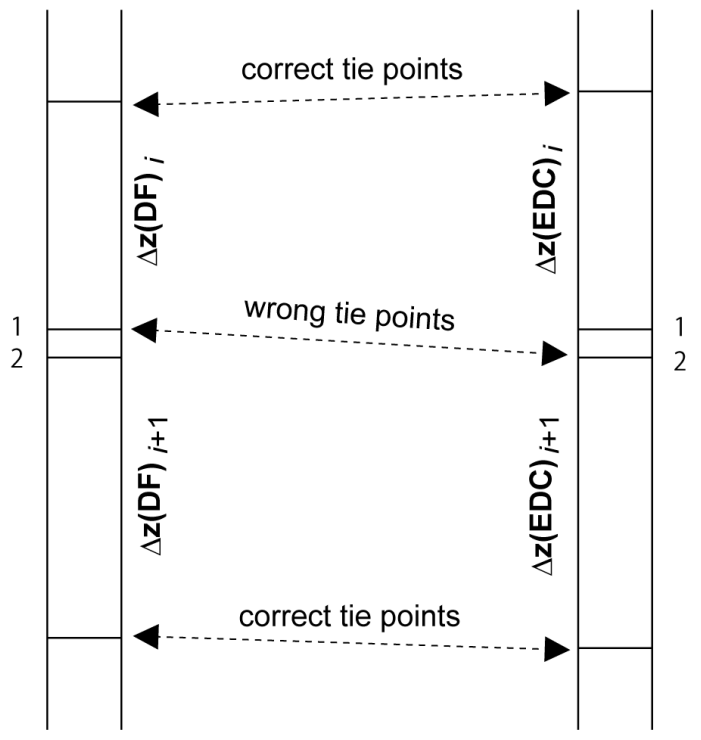

Figure B2. Schematic illustration of choosing the wrong tie points by an operator of the PC interface. The error can occur under conditions described below. (i) The volcanic signal 1 in the DF core and the volcanic signal 2 in the EDC core must be significantly observable. (ii) At the same time, the volcanic signal 1 in the EDC core and the volcanic signal 2 in the DF core must be faint or absent. (iii) These two peaks should be within depths of $\sim 0.1 \mathrm{~m}$ or so of the location expected assuming the layer thickness ratio between the adjacent volcanic match pairs remains constant. Otherwise, the observer will not think that two peak signals are candidates for a true link.

observer will not think that a pair of peak signals are candidates for tie points.

The probability for the occurrence of these three conditions together is very small. From the viewpoint of an operator of the PC interface, almost all tie points were determined without ambiguity, because the operator rarely found indication of confusing candidates for volcanic peaks that could be sources of errors. When we searched for possible candidates for the tie points, we found each pair of candidates in most cases within $0.1 \mathrm{~m}$ of expected depths. We note that the variances of $\sim 0.1 \mathrm{~m}$ are acceptable and understandable considering the past roughness of the Antarctic surface (Barnes et al., 2006). If we find a volcanic signal in one core but not at the expected depth in another core, we just ignore such a single signal and nothing is recorded. It is known that, due to spatial heterogeneity of deposition, a thickness of one year or more deposition is sometimes completely absent in the plateau region of East Antarctica (e.g. Kameda et al., 2008; Koerner, 1971). In the present condition of the Holocene, the probability for the complete absence of an annual layer is greater than $8 \%$ at Dome Fuji. This fact implies that, under conditions of a low accumulation rate in glacial periods, the 
probability for the complete absence of an annual layer is greater. Nevertheless, we are still confident of the identified pattern of peak signals. Thus, a lone peak is not a source of error as far as pattern matching is confidently observed. Figure B3 is given to show that candidates for the tie points were found within narrow depth range.

Along the sequence of the $1401 \mathrm{DF}-\mathrm{EDC}$ tie points, the depth span between adjacent tie points $(\Delta z)$ is calculated for depths of both DF and EDC cores. $\Delta z$ ranged from $0.02 \mathrm{~m}$ (minimum) to $\sim 29 \mathrm{~m}$ (maximum). In Fig. B3, $12 X-Y$ plots, $\Delta z$ at DF versus $\Delta z$ at EDC, made using a logarithmic scale both in $X$ and $Y$ are shown. Figures labelled from a to 1 are for the age span of DFO2006 and at the Marine Isotope Stage (MIS) indicated in each figure. With these figures, we can see how the depth span between adjacent tie points was almost common along the DF core and along the EDC core, with only very small deviations of $\Delta z$ of the order of $0.1 \mathrm{~m}$.

Overall, as mentioned in the main text, determination by an operator was made confidently using the shape, size and synchronicity of the candidate peaks along the two ice cores. Among them, synchronicity within each matched pattern was quite good. As a result, smooth continuity of the trace in Fig. B1 is also good. We therefore argue that they are almost unambiguous tie points, except possible very rare cases of accidental conditions indicated in Fig. B2.

In addition, even if a few erroneous tie points are accidentally included within the 1401 tie points found in this work, error size in depth is of the order of $\sim 0.1 \mathrm{~m}$. Therefore, there will be virtually no impact in further analysis. 

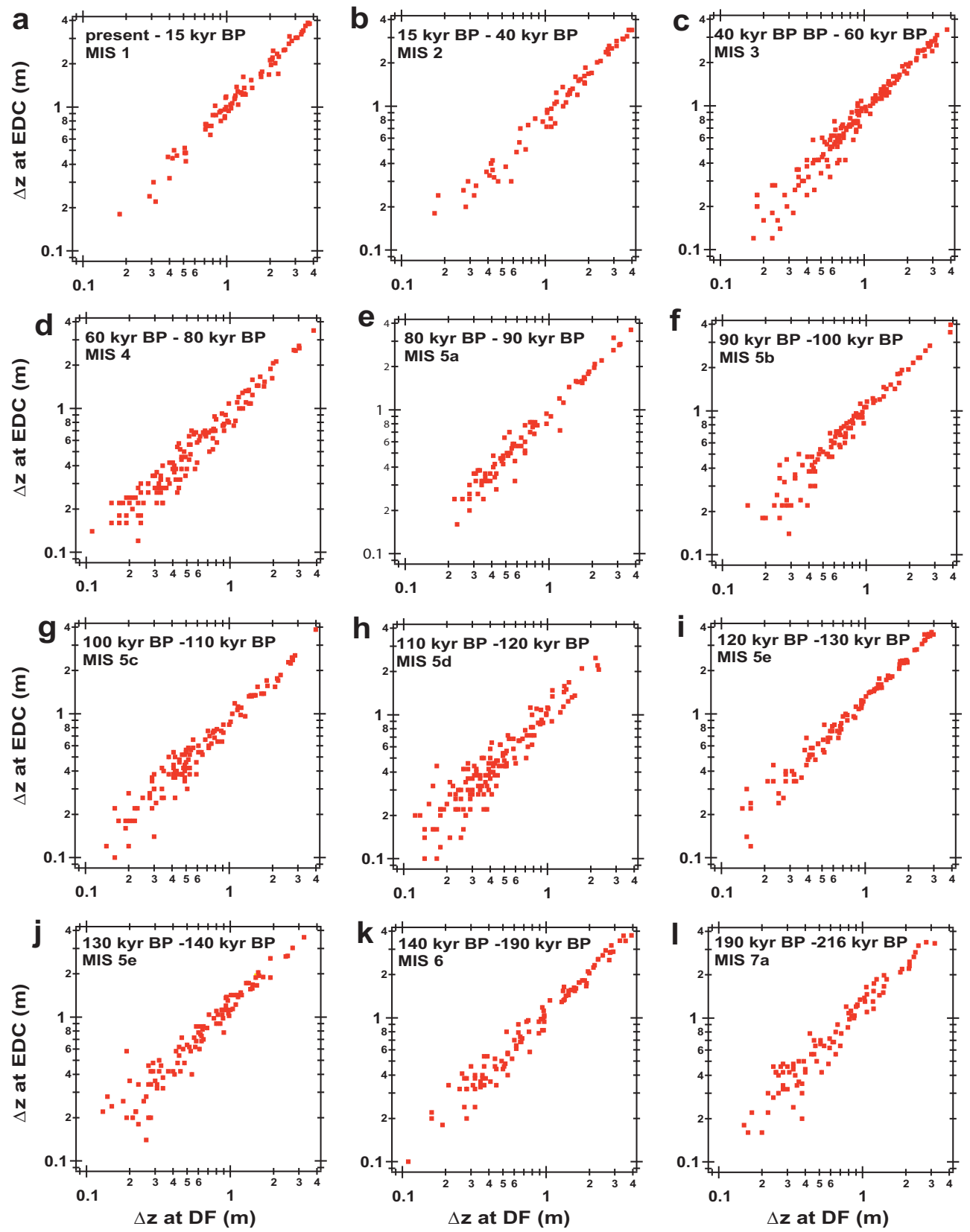

Figure B3. Along the sequence of the $1401 \mathrm{DF}-\mathrm{EDC}$ tie points, the depth spans between adjacent tie points were calculated for depths of both DF and EDC cores. Here, $\Delta z_{i}=z_{i+1}-z_{i}$, where $i$ is an integer from 1 to 1400 . Then, $X-Y$ plots were made as $\Delta z_{i}$ at DF versus $\Delta z_{i}$ at EDC. Figures from a to 1 are for age span on DFO2006 and at the marine isotope stages (MIS) indicated in each figure. With this figure, we can see to what extent depth span between adjacent tie points deviated between $\Delta z_{i}$ at DF and $\Delta z_{i}$ at EDC. We observe that they are in most cases within $\sim 0.1 \mathrm{~m}$. 


\section{The Supplement related to this article is available online at doi:10.5194/cp-11-1395-2015-supplement.}

Author contributions. The writing of this paper was led by the two first authors: S. Fujita and F. Parrenin. Both contributed equally and shared the responsibilities for this paper, carrying out the synchronization work, leading discussions and overseeing the writing of this paper. S. Fujita and H. Motoyama provided the entire electrical profile data of the DF core. E. Wolff and M. Severi provided the EDC electrical profile data and EDC sulfate data, respectively. All authors took part in the scientific discussions.

Acknowledgements. We thank Kenji Kawamura, Ryu Uemura and Valérie Masson-Delmotte for helpful comments on the manuscript. We wish to thank all participants in the field seasons at Dome C. The main logistic support was provided by IPEV and PNRA (at Dome C). This work is a contribution to the European Project for Ice Coring in Antarctica (EPICA), a joint European Science Foundation-European Commission scientific programme, funded by the European Union and by national contributions from Belgium, Denmark, France, Germany, Italy, the Netherlands, Norway, Sweden, Switzerland and the United Kingdom. This is EPICA publication no. 302. We also thank all the Dome Fuji Deep Ice Core Project members who contributed to obtaining the ice core samples, either through logistics, drilling or core processing. The main logistics support was provided by the Japanese Antarctic Research Expedition (JARE), managed by the Ministry of Education, Culture, Sports, Science and Technology (MEXT). This study was supported in part by a grant-in-aid for scientific research (A; 20241007) from the Japan Society for the Promotion of Science (JSPS). The manuscript was prepared with the support of a National Institute of Polar Research (NIPR) publication subsidy. This paper was greatly improved by thoughtful comments by five anonymous referees and by the editor, Ed Brook.

Edited by: E. Brook

\section{References}

Barker, S., Knorr, G., Edwards, R. L., Parrenin, F., Putnam, A. E., Skinner, L. C., Wolff, E., and Ziegler, M.: 800000 years of abrupt climate variability, Science, 334, 347351, doi:10.1126/science.1203580, 2011.

Barnes, P. R. F., Wolff, E. W., Mader, H. M., Udisti, R., Castellano, E., and Röthlisberger, R.: Evolution of chemical peak shapes in the Dome C, Antarctica, ice core, J. Geophys. Res.-Atmos., 108, 4126, doi:10.1029/2002jd002538, 2003.

Barnes, P. R. F., Wolff, E. W., and Mulvaney, R.: A 44 kyr paleoroughness record of the Antarctic surface, J. Geophys. Res.Atmos., 111, D03102, doi:10.1029/2005jd006349, 2006.

Bazin, L., Landais, A., Lemieux-Dudon, B., Toyé Mahamadou Kele, H., Veres, D., Parrenin, F., Martinerie, P., Ritz, C., Capron, E., Lipenkov, V., Loutre, M.-F., Raynaud, D., Vinther, B., Svensson, A., Rasmussen, S. O., Severi, M., Blunier, T., Leuenberger,
M., Fischer, H., Masson-Delmotte, V., Chappellaz, J., and Wolff, E.: An optimized multi-proxy, multi-site Antarctic ice and gas orbital chronology (AICC2012): 120-800 ka, Clim. Past, 9, 17151731, doi:10.5194/cp-9-1715-2013, 2013.

Bender, M. L.: Orbital tuning chronology for the vostok climate record supported by trapped gas composition, Earth Planet. Sci Lett., 204, 274-289, 2002.

Cavitte, M. G. P., Blankenship, D. D., Young, D. A., Siegert, M. J., and Le Meur, E.: Radar stratigraphy connecting Lake Vostok and Dome C, East Antarctica, constrains the EPICA/DMC ice core time scale, The Cryosphere Discuss., 7, 321-342, doi:10.5194/tcd-7-321-2013, 2013.

Cheng, H., Edwards, R. L., Broecker, W. S., Denton, G. H., Kong, X., Wang, Y., Zhang, R., and Wang, X.: Ice age terminations, Science, 326, 248-252, doi:10.1126/science.1177840, 2009.

Cole-Dai, J. H., Mosley-Thompson, E., Wight, S. P., and Thompson, L. G.: A 4100-year record of explosive volcanism from an East Antarctica ice core, J. Geophys. Res., 105, 24431-24441, doi:10.1029/2000jd900254, 2000.

Courville, Z. R., Albert, M. R., Fahnestock, M. A., Cathles , L. M. I., and Shuman, C. A.: Impacts of an accumulation hiatus on the physical properties of firn at a low-accumulation polar site, J. Geophys. Res, 112, F02030, doi:10.1029/2005JF000429, 2007.

EPICA Community Members : Eight glacial cycles from an Antarctic ice core, Nature, 429, 623-628, doi:10.1038/nature02599, 2004.

Fujita, S., Maeno, H., Uratsuka, S., Furukawa, T., Mae, S., Fujii, Y., and Watanabe, O.: Nature of radio-echo layering in the Antarctic ice sheet detected by a two-frequency experiment, J. Geophys. Res., 104, 13013-13024, doi:10.1029/1999JB900034, 1999.

Fujita, S., Azuma, N., Fujii, Y., Kameda, T., Kamiyama, K., Motoyama, H., Narita, H., Shoji, H., and Watanabe, O.: Ice core processing at Dome Fuji Station, Antarctica., Memoirs of National Institute of Polar Research, Special Issue, 275-286, 2002a.

Fujita, S., Azuma, N., Motoyama, H., Kameda, T., Narita, H., Fujii, Y., and Watanabe, O.: Electrical measurements from the 2503 m Dome F Antarctic ice core, Ann. Glaciol., 35, 313-320, doi:10.3189/172756402781816951, 2002b.

Fujita, S., Azuma, N., Motoyama, H., Kameda, T., Narita, H., Fujii, Y., and Watanabe, O.: Linear and non-linear relations between HF conductivity, AC-ECM signals and ECM signals of Dome F Antarctic ice core, from a laboratory experiment, Ann. Glaciol., 35, 321-328, 2002c.

Fujita, S., Okuyama, J., Hori, A., and Hondoh, T.: Metamorphism of stratified firn at Dome Fuji, Antarctica: A mechanism for local insolation modulation of gas transport conditions during bubble close off. , J. Geophys. Res, 114, F03023, doi:10.1029/2008JF001143, 2009.

Fujita, S., Holmlund, P., Matsuoka, K., Enomoto, H., Fukui, K., Nakazawa, F., Sugiyama, S., and Surdyk, S.: Radar diagnosis of the subglacial conditions in Dronning Maud Land, East Antarctica, The Cryosphere, 6, 1203-1219, doi:10.5194/tc-61203-2012, 2012.

Fujita, S., Hirabayashi, M., Goto-Azuma, K., Dallmayr, R., Satow, K., Zheng, J., and Dahl-Jensen, D.: Densification of layered firn of the ice sheet at NEEM, Greenland, J. Glaciol., 60, 905-921, doi:10.3189/2014JoG14J006, 2014.

Gao, C. C., Robock, A., Self, S., Witter, J. B., Steffenson, J. P., Clausen, H. B., Siggaard-Andersen, M. L., Johnsen, S., 
Mayewski, P. A., and Ammann, C.: The 1452 or 1453 AD Kuwae eruption signal derived from multiple ice core records: Greatest volcanic sulphate event of the past 700 years, J. Geophys. Res., 111, D12107, doi:10.1029/2005jd006710, 2006.

Hörhold, M. W., Laepple, T., Freitag, J., Bigler, M., Fischer, H., and Kipfstuhl, S.: On the impact of impurities on the densification of polar firn, Earth Planet. Sci. Lett., 325, 93-99, doi:10.1016/j.epsl.2011.12.022, 2012.

Hammer, C. U.: Acidity of polar ice cores in relation to absolute dating, past volcanism, and radio echoes, J. Glaciol., 25, 359$372,1980$.

Hammer, C. U., Clausen, H. B., and Dansgaard, W.: Greenland ice sheet evidence of post-glacial volcanism and its climatic impact, Nature, 288, 230-235, 1980.

Hutterli, M. A., Schneebeli, M., Freitag, J., Kipfstuhl, J., and Röthlisberger, R.: Impact of local insolation on snow metamorphism and ice core records, Teion Kagaku, Physics of Ice Core Records II : Papers collected after the 2nd International Workshop on Physics of Ice Core Records, edited by: Hondoh, T., held in Sapporo, Japan, 2-6 February 2007, 68, 223-232, 2009.

Jouzel, J., Masson-Delmotte, V., Cattani, O., Dreyfus, G., Falourd, S., Hoffmann, G., Minster, B., Nouet, J., Barnola, J. M., Chappellaz, J., Fischer, H., Gallet, J. C., Johnsen, S., Leuenberger, M., Loulergue, L., Luethi, D., Oerter, H., Parrenin, F., Raisbeck, G., Raynaud, D., Schilt, A., Schwander, J., Selmo, E., Souchez, R., Spahni, R., Stauffer, B., Steffensen, J. P., Stenni, B., Stocker, T. F., Tison, J. L., Werner, M., and Wolff, E. W.: Orbital and millennial antarctic climate variability over the past 800000 years, Science, 317, 793-796, 2007.

Kameda, T., Motoyama, H., Fujita, S., and Takahashi, S.: Temporal and spatial variability of surface mass balance at Dome Fuji, East Antarctica, by the stake method from 1995 to 2006, J. Glaciol., 54, 107-116, doi:10.3189/002214308784409062, 2008.

Kawamura, K., Nakazawa, T., Aoki, S., Fujii, Y., Watanabe, O., and Severinghaus, J.: Close resemblance between local summer insolation, $\mathrm{O}_{2} / \mathrm{N}_{2}$ and total air content from the Dome Fuji ice core, Antarctica, Eos Trans. AGU, 85, Fall Meet. Suppl., Abstract C33C-0356, 2004.

Kawamura, K., Parrenin, F., Lisiecki, L., Uemura, R., Vimeux, F., Severinghaus, J. P., Hutterli, M. A., Nakazawa, T., Aoki, S., Jouzel, J., Raymo, M. E., Matsumoto, K., Nakata, H., Motoyama, H., Fujita, S., Azuma, K., Fujii, Y., and Watanabe, O.: Northern hemisphere forcing of climatic cycles over the past 360000 years implied by accurately dated Antarctic ice cores, Nature, 448, 912-916, doi:10.1038/nature06015, 2007.

Koerner, R. M.: A stratigraphic method of determining the snow accumulation rate at Plateau Station, Antarctica, and application to South Pole-Queen Maud Land traverse 2, 1965-1966, in: Antarctic ice studies ii, edited by: Crary, A. P., American Geophysical Union, Washington D.C., 225-238, 1971.

Kohno, M., Fujii, Y., and Hirata, T.: Chemical composition of volcanic glasses in visible tephra layers found in a $2503 \mathrm{~m}$ deep ice core from Dome Fuji, Antarctica Ann. Glaciol., 39, 576-584, 2004.

Landais, A., Dreyfus, G., Capron, E., Pol, K., Loutre, M. F., Raynaud, D., Lipenkov, V. Y., Arnaud, L., Masson-Delmotte, V., Paillard, D., Jouzel, J., and Leuenberger, M.: Towards orbital dating of the EPICA Dome $\mathrm{C}$ ice core using $\delta \mathrm{O}_{2} / \mathrm{N}_{2}$, Clim. Past, 8, 191-203, doi:10.5194/cp-8-191-2012, 2012.
Lemieux-Dudon, B., Blayo, E., Petit, J.-R., Waelbroeck, C., Svensson, A., Ritz, C., Barnola, J.-M., Narcisi, B. M., and Parrenin, F.: Consistent dating for Antarctic and Greenland ice cores, Quaternary Sci. Rev., 29, 8-20, doi:10.1016/j.quascirev.2009.11.010, 2010.

Lipenkov, V., Raynaud, D., Loutre, M.-F., and Duval, P.: On the potential of coupling air content and $\mathrm{O}_{2} / \mathrm{N}_{2}$ from trapped air for establishing an ice core chronology tuned on local insolation, Quaternary Research Reviews, 30, 3280-3289, doi:10.1016/j.quascirev.2011.07.013, 2011.

Moore, J. C. and Paren, J. G.: A new technique for dielectric logging of Antarctic ice cores, J. Phys., 48, 155-160, 1987.

Motoyama, H.: The second deep ice coring project at Dome Fuji, Antarctica, Scientific Drilling, 5, 41-43, doi:10.2204/Iodp.sd.5.05.2007, 2007.

Narcisi, B., Petit, J. R., Delmonte, B., Basile-Doelsch, I., and Maggi, V.: Characteristics and sources of tephra layers in the Epica-Dome $\mathrm{C}$ ice record (East Antarctica): Implications for past atmospheric circulation and ice core stratigraphic correlations, Earth Planet. Sci. Lett., 239, 253-265, doi:10.1016/j.eps1.2005.09.005, 2005.

Parrenin, F., Rémy, F., Ritz, C., Siegert, M. J., and Jouzel, J.: New modelling of the Vostok ice flow line and implication for the glaciological chronology of the Vostok ice core, J. Geophys. Res.-Atmos., 109, D20102, doi:10.1029/2004jd004561, 2004.

Parrenin, F., Barnola, J.-M., Beer, J., Blunier, T., Castellano, E., Chappellaz, J., Dreyfus, G., Fischer, H., Fujita, S., Jouzel, J., Kawamura, K., Lemieux-Dudon, B., Loulergue, L., MassonDelmotte, V., Narcisi, B., Petit, J.-R., Raisbeck, G., Raynaud, D., Ruth, U., Schwander, J., Severi, M., Spahni, R., Steffensen, J. P., Svensson, A., Udisti, R., Waelbroeck, C., and Wolff, E.: The EDC3 chronology for the EPICA Dome C ice core, Clim. Past, 3, 485-497, doi:10.5194/cp-3-485-2007, 2007a.

Parrenin, F., Dreyfus, G., Durand, G., Fujita, S., Gagliardini, O., Gillet, F., Jouzel, J., Kawamura, K., Lhomme, N., MassonDelmotte, V., Ritz, C., Schwander, J., Shoji, H., Uemura, R., Watanabe, O., and Yoshida, N.: 1-D-ice flow modelling at EPICA Dome C and Dome Fuji, East Antarctica, Clim. Past, 3, 243-259, doi:10.5194/cp-3-243-2007, 2007b.

Parrenin, F., Petit, J.-R., Masson-Delmotte, V., Wolff, E., BasileDoelsch, I., Jouzel, J., Lipenkov, V., Rasmussen, S. O., Schwander, J., Severi, M., Udisti, R., Veres, D., and Vinther, B. M.: Volcanic synchronisation between the EPICA Dome $\mathrm{C}$ and Vostok ice cores (Antarctica) 0-145 kyr BP, Clim. Past, 8, 1031-1045, doi:10.5194/cp-8-1031-2012, 2012.

Petit, J. R., Jouzel, J., Raynaud, D., Barkov, N. I., Barnola, J.-M., Basile, I., Bender, M., Chappellaz, J., Davis, M., Delaygue, G., Delmotte, M., Kotlyakov, V. M., Legrand, M., Lipenkov, V. Y., Lorius, C., Pepin, L., Ritz, C., Saltzman, E., and Stievenard, M.: Climate and atmospheric history of the past 420,000 years from the Vostok ice core, Antarctica, Nature, 399, 429-436, doi:10.1038/20859, 1999.

Raynaud, D., Lipenkov, V., Lemieux-Dudon, B., Duval, P., Loutre, M.-F., and Lhomme, N.: The local insolation signature of air content in antarctic ice. A new step toward an absolute dating of ice records, Earth Planet. Sci. Lett., 261, 337-349, doi:10.1016/j.eps1.2007.06.025, 2007.

Ruth, U., Barnola, J.-M., Beer, J., Bigler, M., Blunier, T., Castellano, E., Fischer, H., Fundel, F., Huybrechts, P., Kaufmann, P., 
Kipfstuhl, S., Lambrecht, A., Morganti, A., Oerter, H., Parrenin, F., Rybak, O., Severi, M., Udisti, R., Wilhelms, F., and Wolff, E.: "EDML1": a chronology for the EPICA deep ice core from Dronning Maud Land, Antarctica, over the last 150000 years, Clim. Past, 3, 475-484, doi:10.5194/cp-3-475-2007, 2007.

Severi, M., Becagli, S., Castellano, E., Morganti, A., Traversi, R., Udisti, R., Ruth, U., Fischer, H., Huybrechts, P., Wolff, E., Parrenin, F., Kaufmann, P., Lambert, F., and Steffensen, J. P.: Synchronisation of the EDML and EDC ice cores for the last $52 \mathrm{kyr}$ by volcanic signature matching, Clim. Past, 3, 367-374, doi:10.5194/cp-3-367-2007, 2007.

Severi, M., Udisti, R., Becagli, S., Stenni, B., and Traversi, R.: Volcanic synchronisation of the EPICA-DC and TALDICE ice cores for the last $42 \mathrm{kyr}$ BP, Clim. Past, 8, 509-517, doi:10.5194/cp-8509-2012, 2012.

Steinhage, D., Kipfstuhl, S., Nixdorf, U., and Miller, H.: Internal structure of the ice sheet between Kohnen Station and Dome Fuji, Antarctica, revealed by airborne radio-echo sounding, Ann. Glaciol., 54, 163-167, doi:10.3189/2013AoG64A113, 2013.

Suwa, M. and Bender, M. L.: Chronology of the Vostok ice core constrained by $\mathrm{O}_{2} / \mathrm{N}_{2}$ ratios of occluded air, and its implication for the Vostok climate records, Quaternary Sci. Rev., 27, 10931106, doi:10.1016/j.quascirev.2008.02.017, 2008.

Svensson, A., Bigler, M., Blunier, T., Clausen, H. B., Dahl-Jensen, D., Fischer, H., Fujita, S., Goto-Azuma, K., Johnsen, S. J., Kawamura, K., Kipfstuhl, S., Kohno, M., Parrenin, F., Popp, T., Rasmussen, S. O., Schwander, J., Seierstad, I., Severi, M., Steffensen, J. P., Udisti, R., Uemura, R., Vallelonga, P., Vinther, B. M., Wegner, A., Wilhelms, F., and Winstrup, M.: Direct linking of Greenland and Antarctic ice cores at the Toba eruption (74 ka BP), Clim. Past, 9, 749-766, doi:10.5194/cp-9-749-2013, 2013.

Tabacco, I. E., Passerini, A., Corbelli, F., and Gorman, M.: Determination of the surface and bed topography at Dome C, East Antarctica, J. Glaciol., 44, 185-191, 1998.

Traversi, R., Becagli, S., Castellano, E., Migliori, A., Severi, M., and Udisti, R.: High-resolution fast ion chromatography (FIC) measurements of chloride, nitrate and sulphate along the EPICA Dome C ice core, in: Ann. Glaciol., edited by: Wolff, E. W., Ann. Glaciol.-Series, 35, 291-298, 2002.

Udisti, R., Becagli, S., Castellano, E., Mulvaney, R., Schwander, J., Torcini, S., and Wolff, E.: Holocene electrical and chemical measurements from the EPICA-Dome C ice core, in: Ann. Glaciol., vol 30, 2000, edited by: Hutter, K., Ann. Glaciol., Int Glaciological Soc, Cambridge, 20-26, 2000.
Udisti, R., Becagli, S., Castellano, E., Delmonte, B., Jouzel, J., Petit, J. R., Schwander, J., Stenni, B., and Wolff, E. W.: Stratigraphic correlations between the European Project for Ice Coring in Antarctica (EPICA) Dome C and Vostok ice cores showing the relative variations of snow accumulation over the past $45 \mathrm{kyr}$, J. Geophys. Res., 109, D08101, doi:10.1029/2003jd004180, 2004.

Uemura, R., Masson-Delmotte, V., Jouzel, J., Landais, A., Motoyama, H., and Stenni, B.: Ranges of moisture-source temperature estimated from Antarctic ice cores stable isotope records over glacial-interglacial cycles, Clim. Past, 8, 11091125, doi:10.5194/cp-8-1109-2012, 2012.

Veres, D., Bazin, L., Landais, A., Toyé Mahamadou Kele, H., Lemieux-Dudon, B., Parrenin, F., Martinerie, P., Blayo, E., Blunier, T., Capron, E., Chappellaz, J., Rasmussen, S. O., Severi, M., Svensson, A., Vinther, B., and Wolff, E. W.: The Antarctic ice core chronology (AICC2012): an optimized multi-parameter and multi-site dating approach for the last 120 thousand years, Clim. Past, 9, 1733-1748, doi::10.5194/cp-9-1733-2013, 2013.

WAIS Divide Project Members: Precise interpolar phasing of abrupt climate change during the last ice age, Nature, 520, 661-665, doi:10.1038/nature14401, 2015.

Watanabe, O., Kamiyama, K., Motoyama, H., Fujii, Y., Shoji, H., and Satow, K.: The paleoclimate record in the ice core at Dome Fuji station, East Antarctica, Ann. Glaciol., 29, 176-178, doi:10.3189/172756499781821553, 1999.

Watanabe, O., Jouzel, J., Johnsen, S., Parrenin, F., Shoji, H., and Yoshida, N.: Homogeneous climate variability across East Antarctica over the past three glacial cycles, Nature, 422, 509512, doi:10.1038/nature01525, 2003.

Wilhelms, F., Kipfstuhl, J., Miller, H., Heinloth, K., and Firestone, J.: Precise dielectric profiling of ice cores: A new device with improved guarding and its theory, J. Glaciol., 44, 171-174, 1998.

Wolff, E. W.: Electrical stratigraphy of polar ice cores: Principles, methods, and findings, in: Physics of ice core records, edited by: Hondoh, T., Hokkaido University Press, Sapporo, 155-171, 2000.

Wolff, E. W., Cook, E., Barnes, P. R. F., and Mulvaney, R.: Signal variability in replicate ice cores, J. Glaciol., 51, 462-468, doi:10.3189/172756505781829197, 2005. 